\title{
Diorganyl Dichalcogenides-Promoted
}

\section{Nucleophilic Closure of 1,4-Diyn-3-ols:}

\section{Synthesis of 2-Benzoyl Chalcogenophenes}

\author{
Juliano A. Roehrs, ${ }^{\dagger}$ Renan P. Pistoia, ${ }^{\dagger}$ Davi F. Back, ${ }^{\ddagger}$ and Gilson Zeni ${ }^{\dagger, *}$
}

†Laboratório de Síntese, Reatividade, Avaliação Farmacológica e Toxicológica de Organocalcogênios and ₹Laboratório de Materiais Inorgânicos, CCNE, Universidade Federal de Santa Maria, Santa Maria, Rio Grande do Sul, 97105-900, Brazil

"gzeni@ufsm.br

\section{SUPPORTING INFORMATION}

Table of Contents

X-Ray crystallography

Figure S1. ORTEP structures of compounds $\mathbf{2} \mathbf{j}$

Table S1. Crystal data and structure refinement for $\mathbf{2 j}$.

Table S2. Bond lengths $[\mathrm{A}]$ and angles $[\mathrm{deg}]$ for $\mathbf{2} \mathbf{j}$. 


\section{X-Ray crystallography}

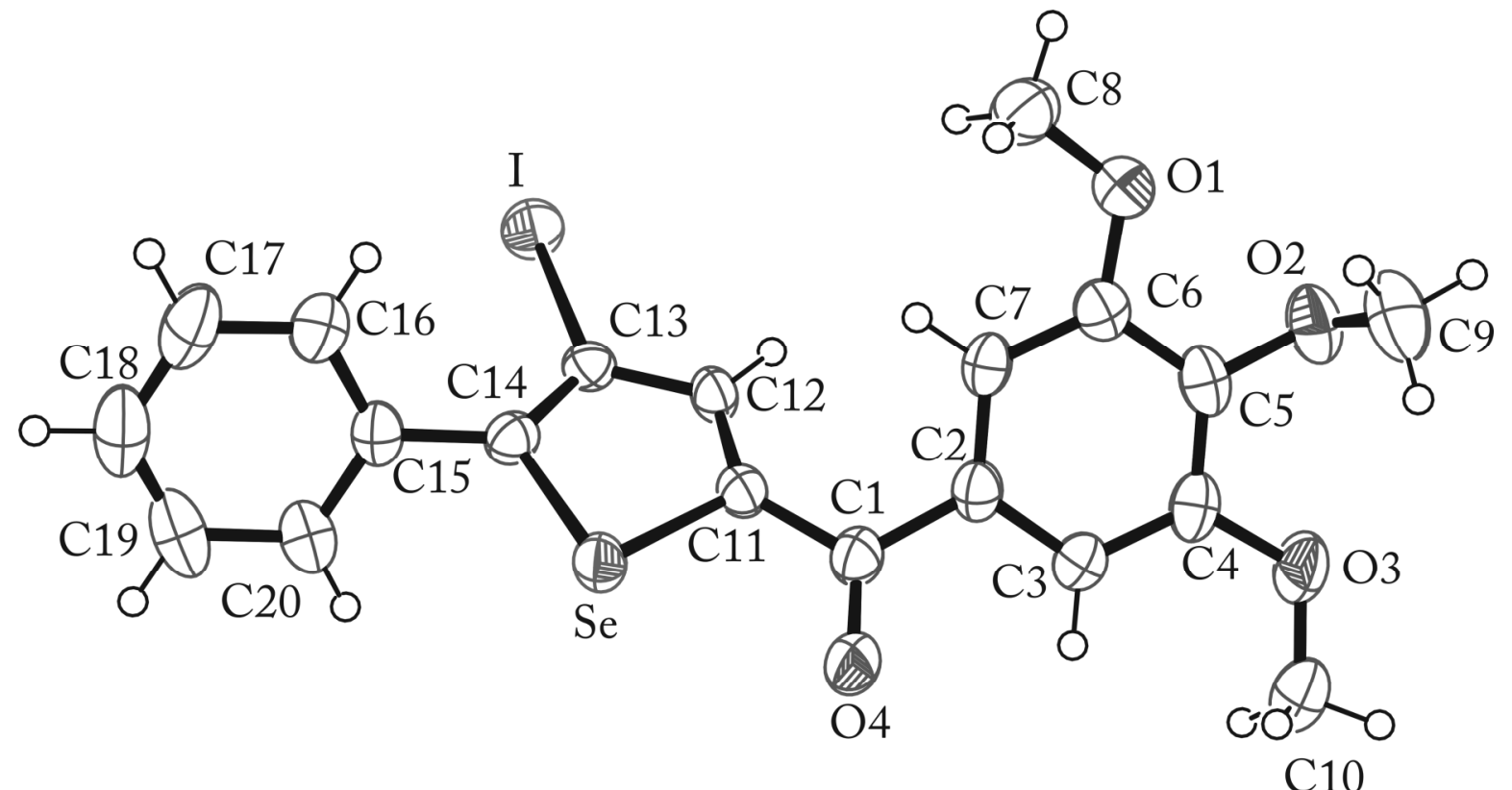

Figure S1. The molecular structure with the atom-labeling scheme of the compound 2j with 50\% thermal ellipsoids using ORTEP software (CCDC 1029272). ${ }^{1}$

Data were collected with single crystal X-ray diffractometer and graphitemonochromatized Mo- $K_{\alpha}$ radiation. The structure was solved by direct methods using SHELXS. ${ }^{2}$ Subsequent Fourier-difference map analyses yielded the positions of the non-hydrogen atoms. Refinements were carried out with the SHELXL package. ${ }^{1}$ All refinements were made by full-matrix least-squares on $F^{2}$ with anisotropic displacement parameters for all non-hydrogen atoms. Hydrogen atoms were included in the refinement in calculated positions but the atoms (of hydrogens) that are commenting performing special bond were located in the Fourier map. Drawings were done using ORTEP3 for Windows. ${ }^{3}$ Crystal data and more details of the data collection and refinements of the $\mathbf{2 j}$ contained in Table S1. Other relevant bond lengths and angles for the x-ray structural parameter analysis of $\mathbf{2} \mathbf{j}$ in Table $\mathbf{S} 2$.

\footnotetext{
${ }^{1}$ CCDC 1029272 contain the supplementary crystallographic data for this paper. These data can be obtained free of charge at http://www.ccdc.cam.ac.uk/conts/retriev-ing.html, or from the Cambridge Crystallographic Data Centre at 12 Union Road, Cambridge CB2 1EZ, UK; fax: (+44) 1223-336-033; or e-mail: deposit@ccdc.cam.ac.uk

2 Sheldrick, G. M. Acta Cryst. A 2008, 64, 110.

${ }^{3}$ ORTEP3 for Windows - Farrugia, L. J. J. Appl. Crystallogr. 1997, 30, 565.
} 
Table S1. Crystal data and structure refinement for $\mathbf{2 j}$.

Compound

Empirical formula

Formula weight

Temperature

Wavelength

Crystal system,

space group

Unit cell dimensions

$$
a, b, c(\AA)
$$

$\alpha, \beta, \gamma\left(^{\circ}\right)$

Volume $\mathrm{A}^{-3}$

Z, Calculated density $\mathrm{Mg} / \mathrm{m}^{-3}$

Absorption coefficient $\mathrm{mm}^{-1}$

$\mathrm{F}(000)$

Crystal size mm

Theta range for data collection deg.

Limiting indices

Reflections collected / unique
$2 \mathbf{j}$

$$
\mathrm{C}_{20} \mathrm{H}_{17} \mathrm{I} \mathrm{O}_{4} \mathrm{Se}
$$

527.20

290(2) K

$0.71073 \mathrm{~A}$

Triclinic, P21/c

$$
\begin{gathered}
a=8.3426(3) \\
b=7.7556(3) \\
c=30.4400(10) \\
\alpha=90 \\
\beta=93.011(2) \\
\gamma=90
\end{gathered}
$$

1966.81(12)

4, 1.780

3.500

1024

$$
0.506 \times 0.410 \times 0.120
$$

1.34 to 27.27

$-10<=\mathrm{h}<=10$,

$-9<=\mathrm{k}<=9$,

$-39<=1<=39$

$27607 / 4385[\mathrm{R}($ int $)=0.0382]$ 
Completeness to theta

Absorption correction

Max. and min. transmission

Refinement method

Data/restraints/ parameters

Goodness-of-fit on $\mathrm{F}^{2}$

Final $\mathrm{R}$ indices [I $>2 \operatorname{sigma}(\mathrm{I})]$

$\mathrm{R}$ indices (all data)

Largest diff. peak and hole e. $\mathrm{A}^{-3}$
$99.6 \%$

Numerical

0.699 and 0.219

Full-matrix least-squares on $\mathrm{F}^{2}$

4385 / 0 / 235

1.223

$\mathrm{R} 1=0.0401, \mathrm{wR} 2=0.1039$

$\mathrm{R} 1=0.0509, \mathrm{wR} 2=0.1184$

0.986 and -0.612

Table S2. Bond lengths [A] and angles [deg] for 2j.

\begin{tabular}{|l|l|l|l|}
\hline \multicolumn{2}{|c|}{ Bond lengths } & \multicolumn{2}{c|}{ Angles } \\
\hline $\mathrm{C}(1)-\mathrm{O}(4)$ & $1.214(6)$ & $\mathrm{O}(4)-\mathrm{C}(1)-\mathrm{C}(11)$ & $118.9(4)$ \\
\hline $\mathrm{C}(1)-\mathrm{C}(11)$ & $1.472(6)$ & $\mathrm{O}(4)-\mathrm{C}(1)-\mathrm{C}(2)$ & $120.9(4)$ \\
\hline $\mathrm{C}(1)-\mathrm{C}(2)$ & $1.498(6)$ & $\mathrm{C}(11)-\mathrm{C}(1)-\mathrm{C}(2)$ & $120.2(4)$ \\
\hline $\mathrm{C}(2)-\mathrm{C}(3)$ & $1.382(6)$ & $\mathrm{C}(3)-\mathrm{C}(2)-\mathrm{C}(7)$ & $120.8(4)$ \\
\hline $\mathrm{C}(2)-\mathrm{C}(7)$ & $1.388(7)$ & $\mathrm{C}(3)-\mathrm{C}(2)-\mathrm{C}(1)$ & $117.3(4)$ \\
\hline $\mathrm{C}(3)-\mathrm{C}(4)$ & $1.392(6)$ & $\mathrm{C}(7)-\mathrm{C}(2)-\mathrm{C}(1)$ & $121.6(4)$ \\
\hline $\mathrm{C}(4)-\mathrm{O}(3)$ & $1.365(5)$ & $\mathrm{C}(2)-\mathrm{C}(3)-\mathrm{C}(4)$ & $120.0(5)$ \\
\hline $\mathrm{C}(4)-\mathrm{C}(5)$ & $1.387(7)$ & $\mathrm{O}(3)-\mathrm{C}(4)-\mathrm{C}(5)$ & $115.6(4)$ \\
\hline $\mathrm{C}(5)-\mathrm{O}(2)$ & $1.364(5)$ & $\mathrm{O}(3)-\mathrm{C}(4)-\mathrm{C}(3)$ & $124.9(5)$ \\
\hline $\mathrm{C}(5)-\mathrm{C}(6)$ & $1.395(6)$ & $\mathrm{C}(5)-\mathrm{C}(4)-\mathrm{C}(3)$ & $119.5(4)$ \\
\hline $\mathrm{C}(6)-\mathrm{O}(1)$ & $1.363(6)$ & $\mathrm{O}(2)-\mathrm{C}(5)-\mathrm{C}(4)$ & $120.8(4)$ \\
\hline $\mathrm{C}(6)-\mathrm{C}(7)$ & $1.388(6)$ & $\mathrm{O}(2)-\mathrm{C}(5)-\mathrm{C}(6)$ & $118.9(5)$ \\
\hline $\mathrm{C}(8)-\mathrm{O}(1)$ & $1.417(7)$ & $\mathrm{C}(4)-\mathrm{C}(5)-\mathrm{C}(6)$ & $120.2(4)$ \\
\hline $\mathrm{C}(9)-\mathrm{O}(2)$ & $1.406(7)$ & $\mathrm{O}(1)-\mathrm{C}(6)-\mathrm{C}(7)$ & $124.3(4)$ \\
\hline $\mathrm{C}(10)-\mathrm{O}(3)$ & $1.405(7)$ & $\mathrm{O}(1)-\mathrm{C}(6)-\mathrm{C}(5)$ & $115.6(4)$ \\
\hline $\mathrm{C}(11)-\mathrm{C}(12)$ & $1.345(6)$ & $\mathrm{C}(7)-\mathrm{C}(6)-\mathrm{C}(5)$ & $120.0(5)$ \\
\hline $\mathrm{C}(11)-\mathrm{Se}$ & $1.869(4)$ & $\mathrm{C}(6)-\mathrm{C}(7)-\mathrm{C}(2)$ & $119.4(4)$ \\
\hline $\mathrm{C}(12)-\mathrm{C}(13)$ & $1.422(5)$ & $\mathrm{C}(12)-\mathrm{C}(11)-\mathrm{C}(1)$ & $134.1(4)$ \\
\hline $\mathrm{C}(13)-\mathrm{C}(14)$ & $1.355(6)$ & $\mathrm{C}(12)-\mathrm{C}(11)-\mathrm{Se}$ & $111.2(3)$ \\
\hline $\mathrm{C}(13)-\mathrm{I}$ & $2.087(4)$ & $\mathrm{C}(1)-\mathrm{C}(11)-\mathrm{Se}$ & $114.6(3)$ \\
\hline $\mathrm{C}(14)-\mathrm{C}(15)$ & $1.477(5)$ & $\mathrm{C}(11)-\mathrm{C}(12)-\mathrm{C}(13)$ & $114.9(4)$ \\
\hline $\mathrm{C}(14)-\mathrm{Se}$ & $1.869(4)$ & $\mathrm{C}(14)-\mathrm{C}(13)-\mathrm{C}(12)$ & $116.1(4)$ \\
\hline $\mathrm{C}(15)-\mathrm{C}(20)$ & $1.382(7)$ & $\mathrm{C}(14)-\mathrm{C}(13)-\mathrm{I}$ & $123.4(3)$ \\
\hline $\mathrm{C}(15)-\mathrm{C}(16)$ & $1.382(7)$ & $\mathrm{C}(12)-\mathrm{C}(13)-\mathrm{I}$ & $120.5(3)$ \\
\hline $\mathrm{C}(16)-\mathrm{C}(17)$ & $1.390(7)$ & $\mathrm{C}(13)-\mathrm{C}(14)-\mathrm{C}(15)$ & $132.0(4)$ \\
\hline $\mathrm{C}(17)-\mathrm{C}(18)$ & $1.375(9)$ & $\mathrm{C}(13)-\mathrm{C}(14)-\mathrm{Se}$ & $110.2(3)$ \\
\hline & & & \\
\hline
\end{tabular}




\begin{tabular}{|l|l|l|l|}
\hline $\mathrm{C}(18)-\mathrm{C}(19)$ & $1.343(9)$ & $\mathrm{C}(15)-\mathrm{C}(14)-\mathrm{Se}$ & $117.8(3)$ \\
\hline $\mathrm{C}(19)-\mathrm{C}(20)$ & $1.399(7)$ & $\mathrm{C}(20)-\mathrm{C}(15)-\mathrm{C}(16)$ & $119.2(4)$ \\
\hline & & $\mathrm{C}(20)-\mathrm{C}(15)-\mathrm{C}(14)$ & $120.2(4)$ \\
\hline & & $\mathrm{C}(16)-\mathrm{C}(15)-\mathrm{C}(14)$ & $120.6(4)$ \\
\hline & & $\mathrm{C}(15)-\mathrm{C}(16)-\mathrm{C}(17)$ & $120.0(5)$ \\
\hline & & $\mathrm{C}(18)-\mathrm{C}(17)-\mathrm{C}(16)$ & $120.2(6)$ \\
\hline & & $\mathrm{C}(19)-\mathrm{C}(18)-\mathrm{C}(17)$ & $120.0(5)$ \\
\hline & & $\mathrm{C}(18)-\mathrm{C}(19)-\mathrm{C}(20)$ & $121.1(6)$ \\
\hline & & $\mathrm{C}(15)-\mathrm{C}(20)-\mathrm{C}(19)$ & $119.6(5)$ \\
\hline & & $\mathrm{C}(6)-\mathrm{O}(1)-\mathrm{C}(8)$ & $117.9(4)$ \\
\hline & & $\mathrm{C}(5)-\mathrm{O}(2)-\mathrm{C}(9)$ & $115.4(4)$ \\
\hline & & $\mathrm{C}(4)-\mathrm{O}(3)-\mathrm{C}(10)$ & $118.2(4)$ \\
\hline & & $\mathrm{C}(14)-\mathrm{Se}-\mathrm{C}(11)$ & $87.52(19)$ \\
\hline
\end{tabular}


Selected Spectra
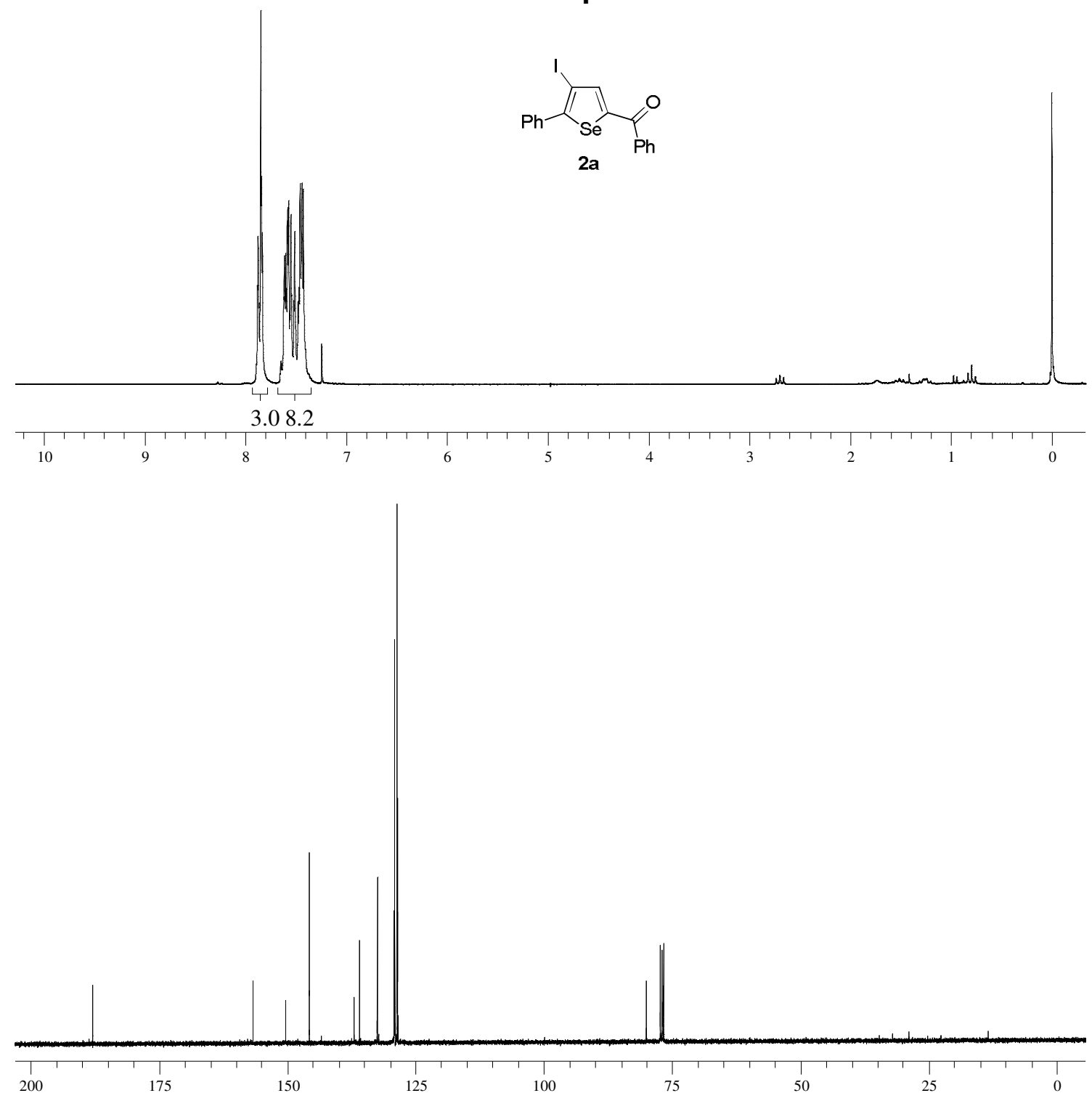

6 


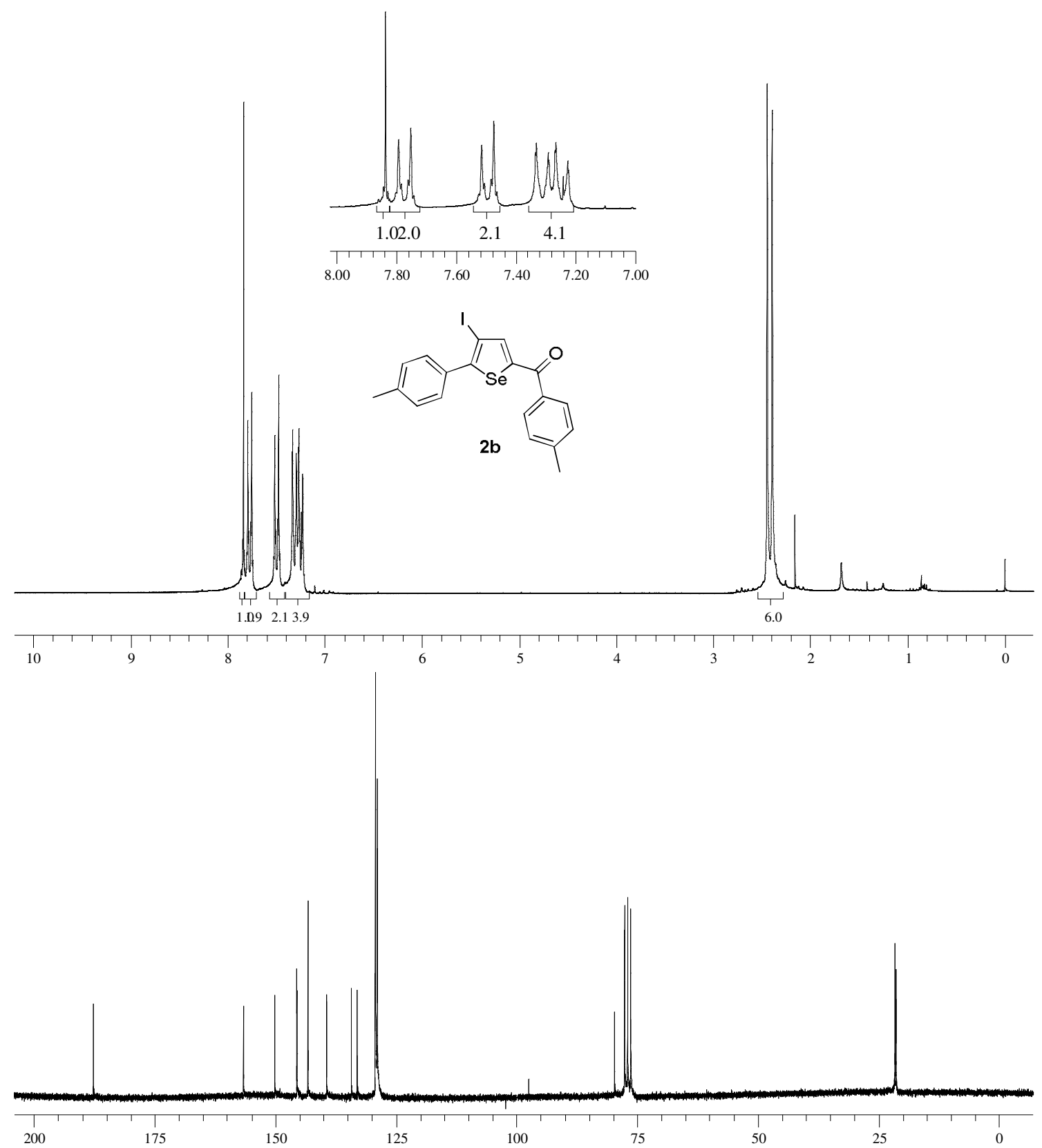




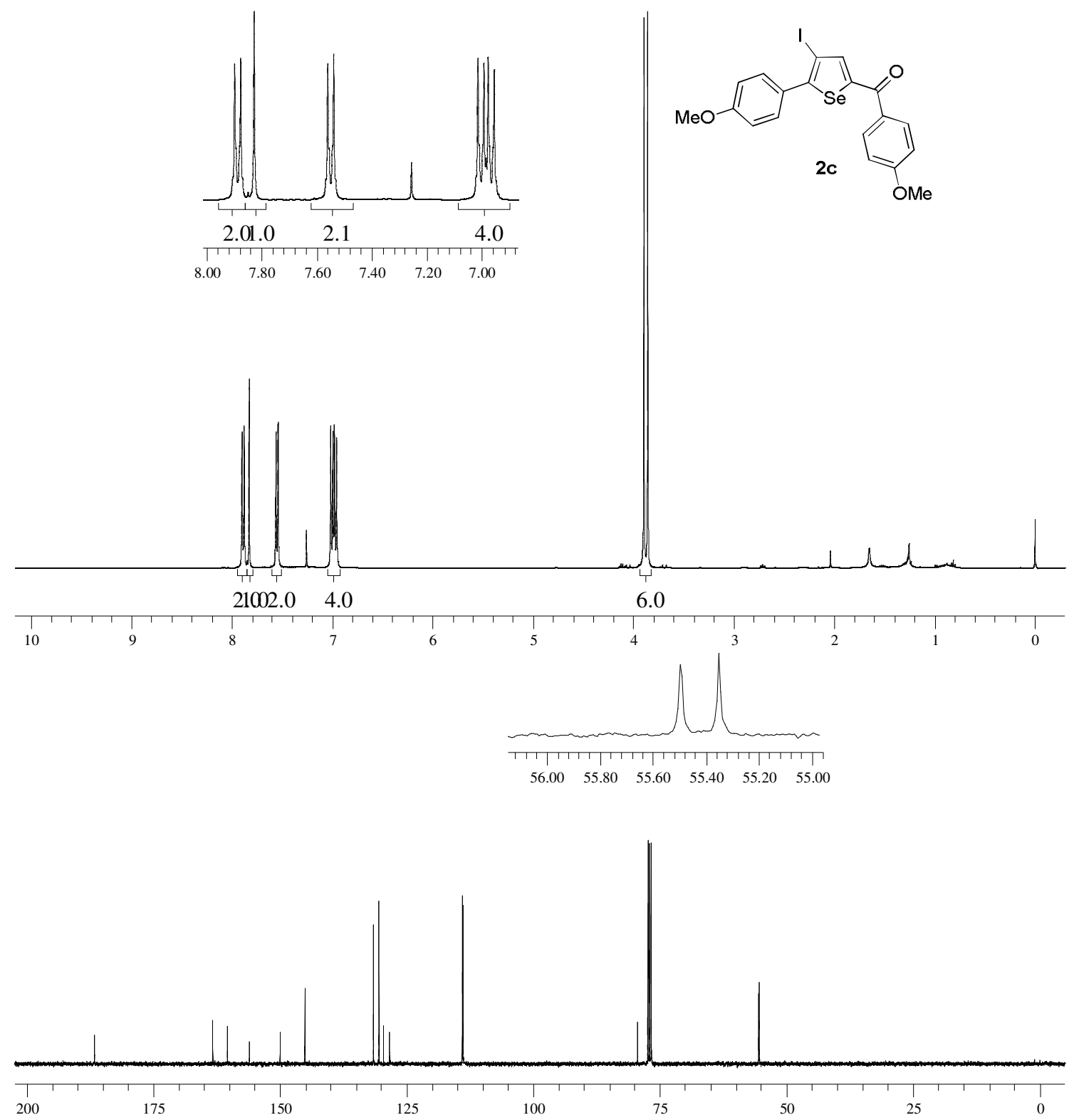




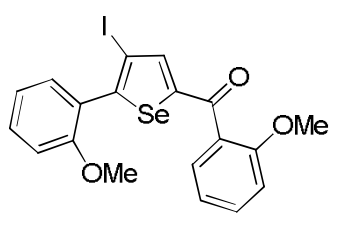

2d
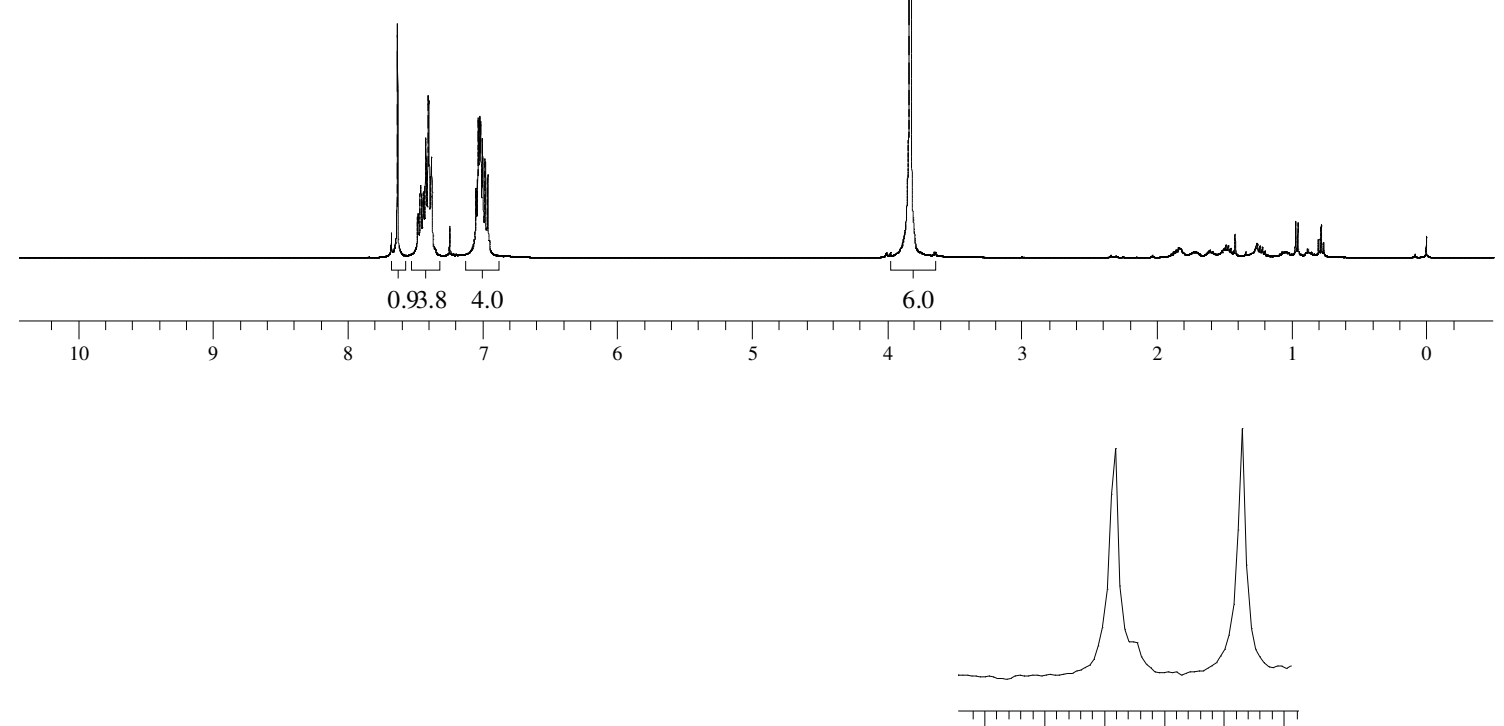

$\begin{array}{llllll}55.90 & 55.80 & 55.70 & 55.60 & 55.50 & 55.40\end{array}$

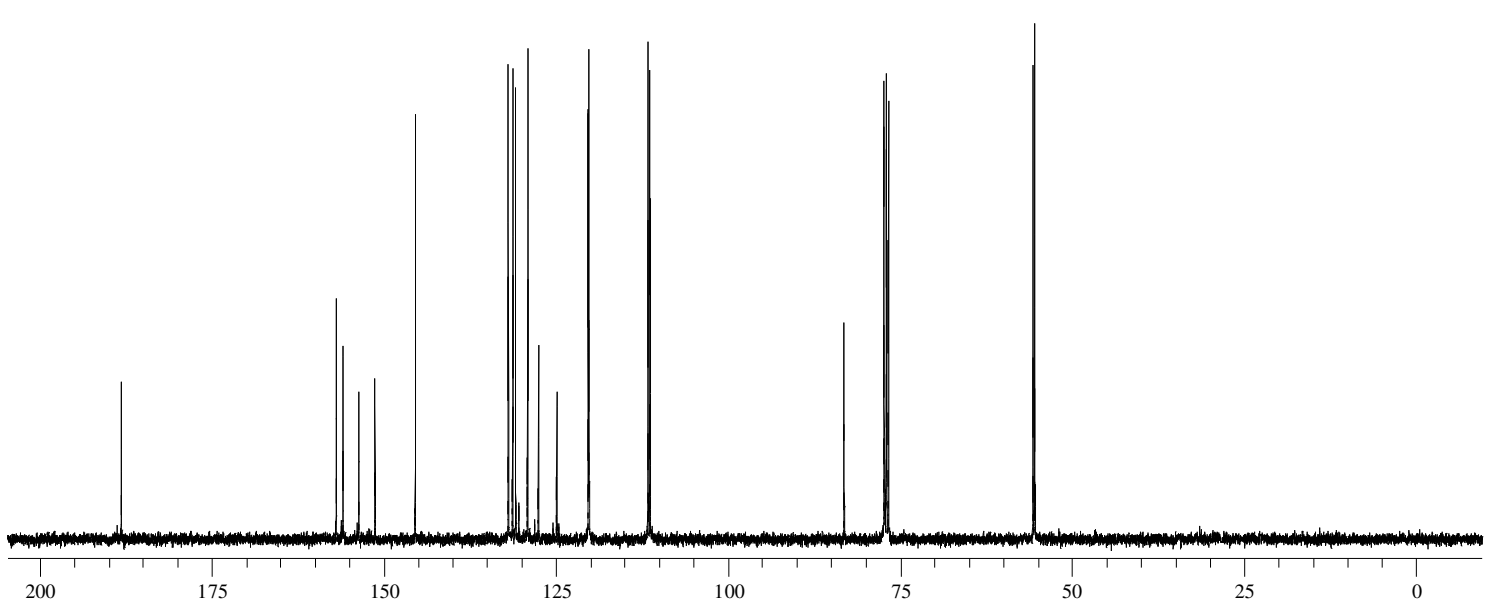



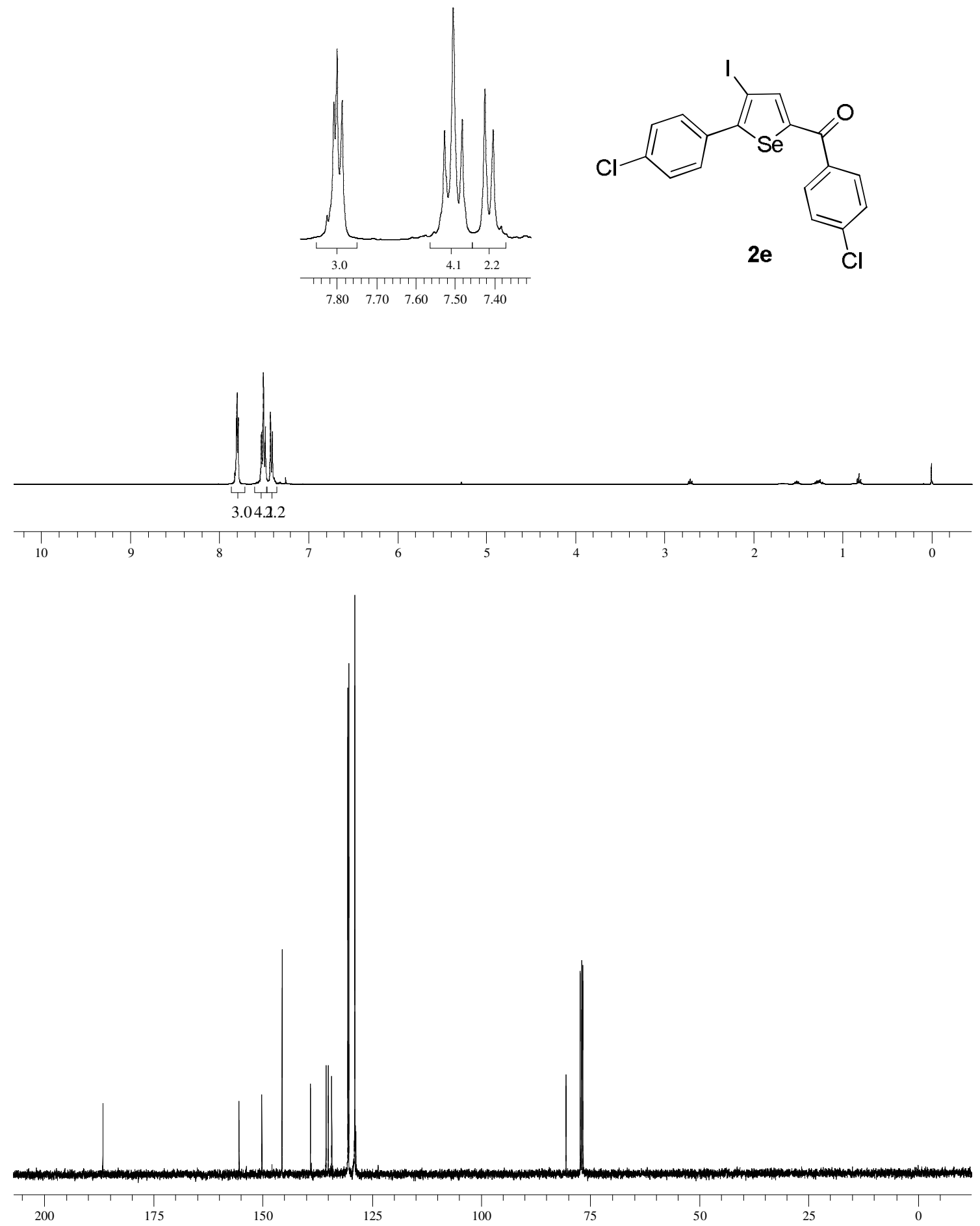


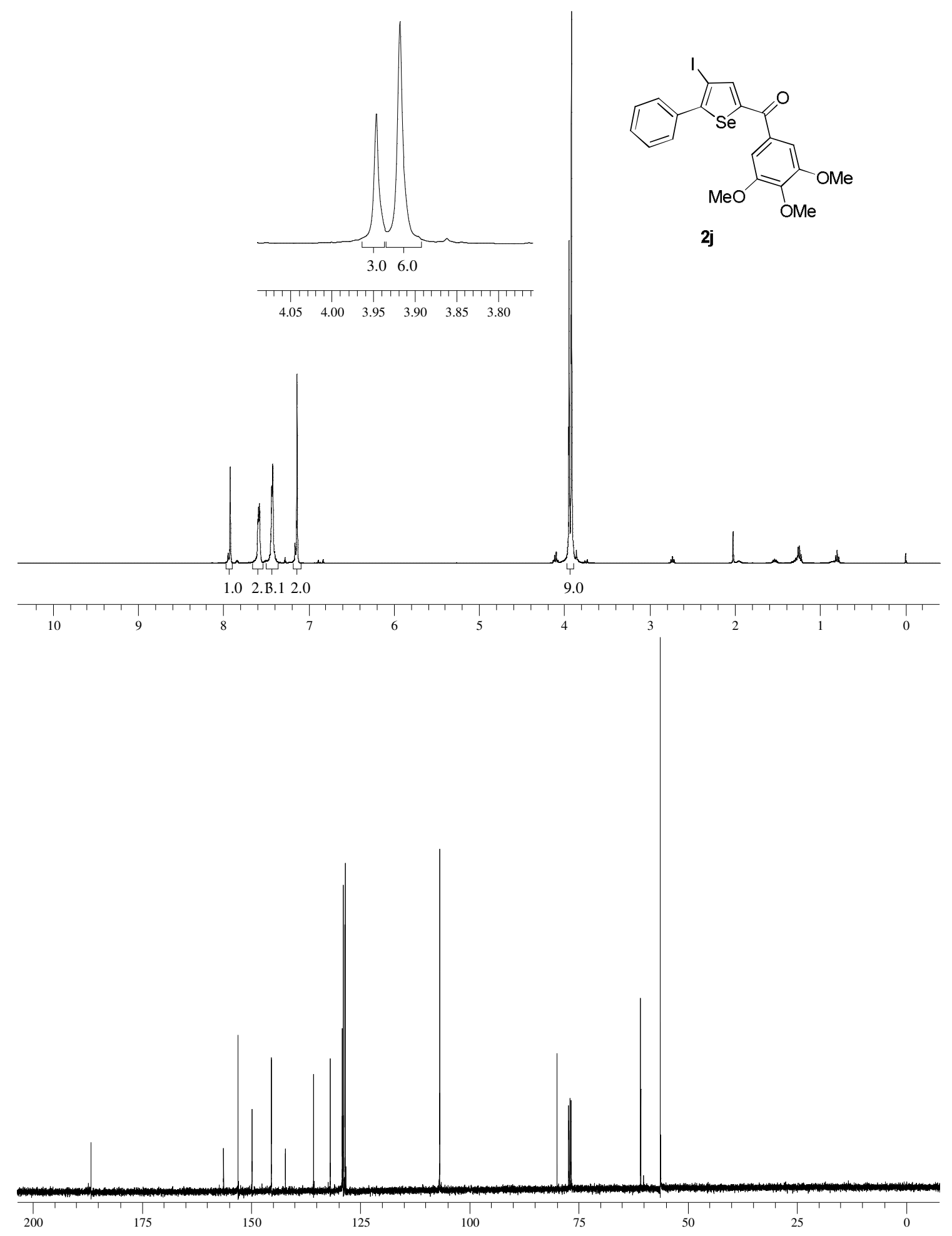




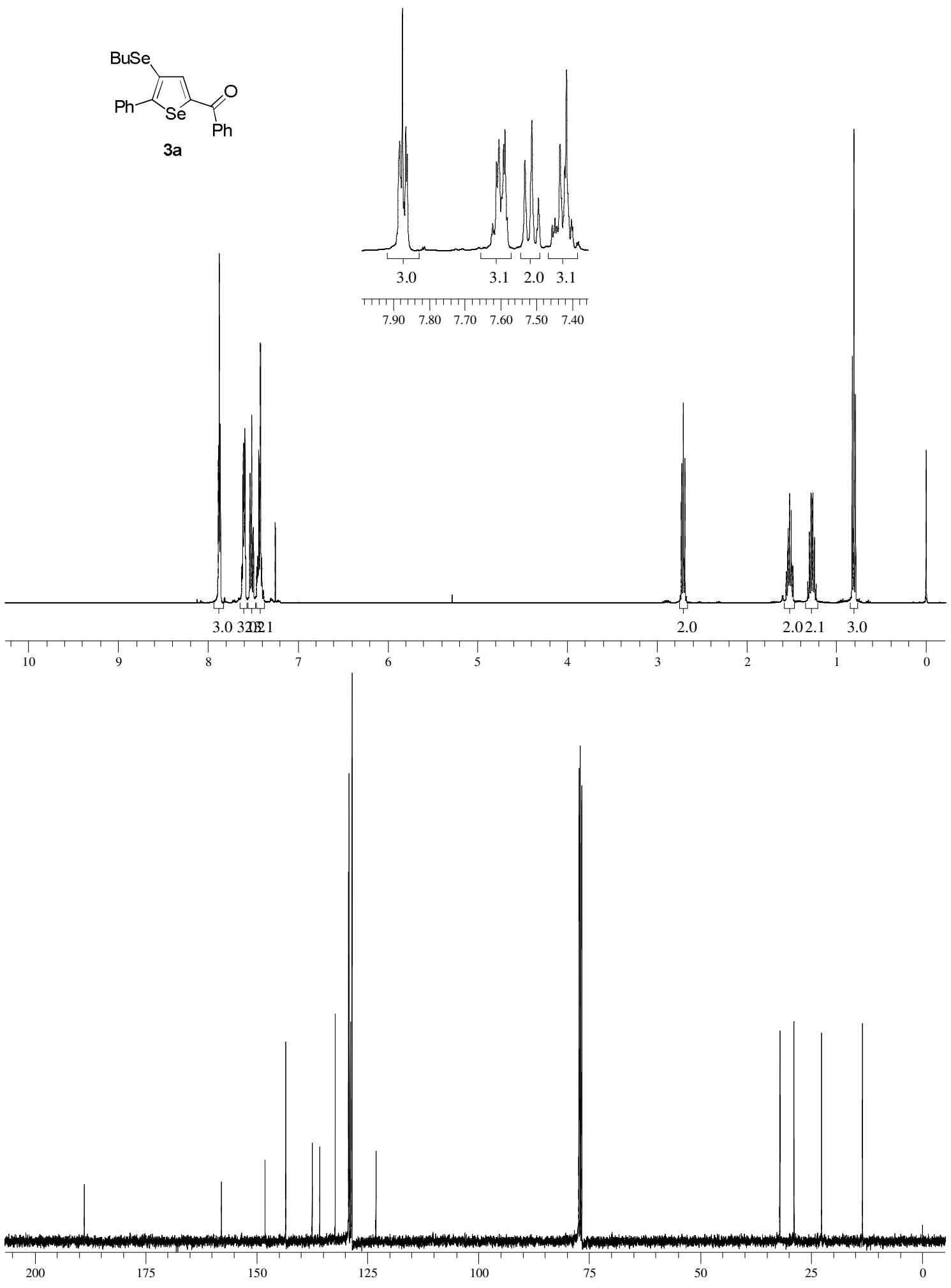

12 


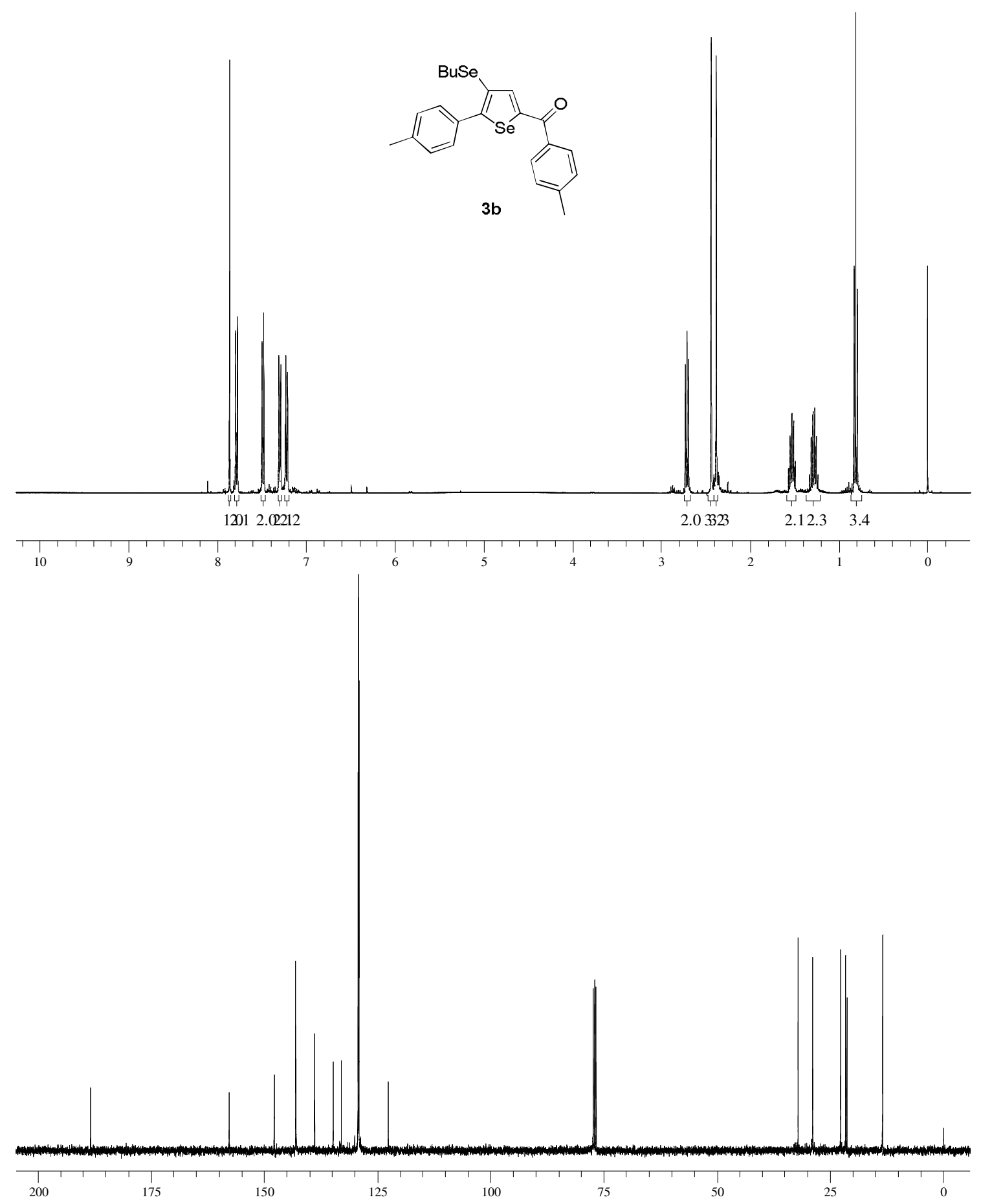



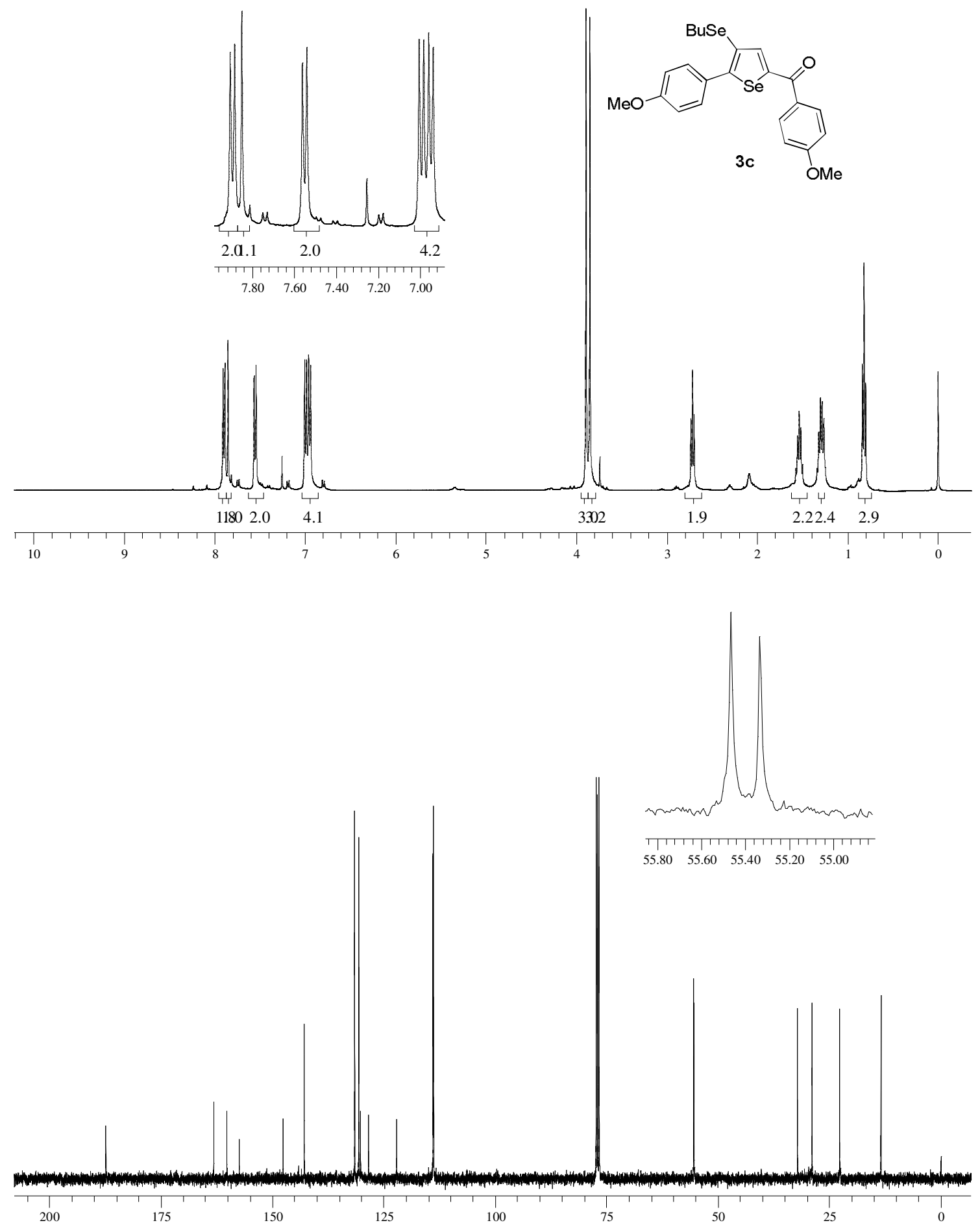

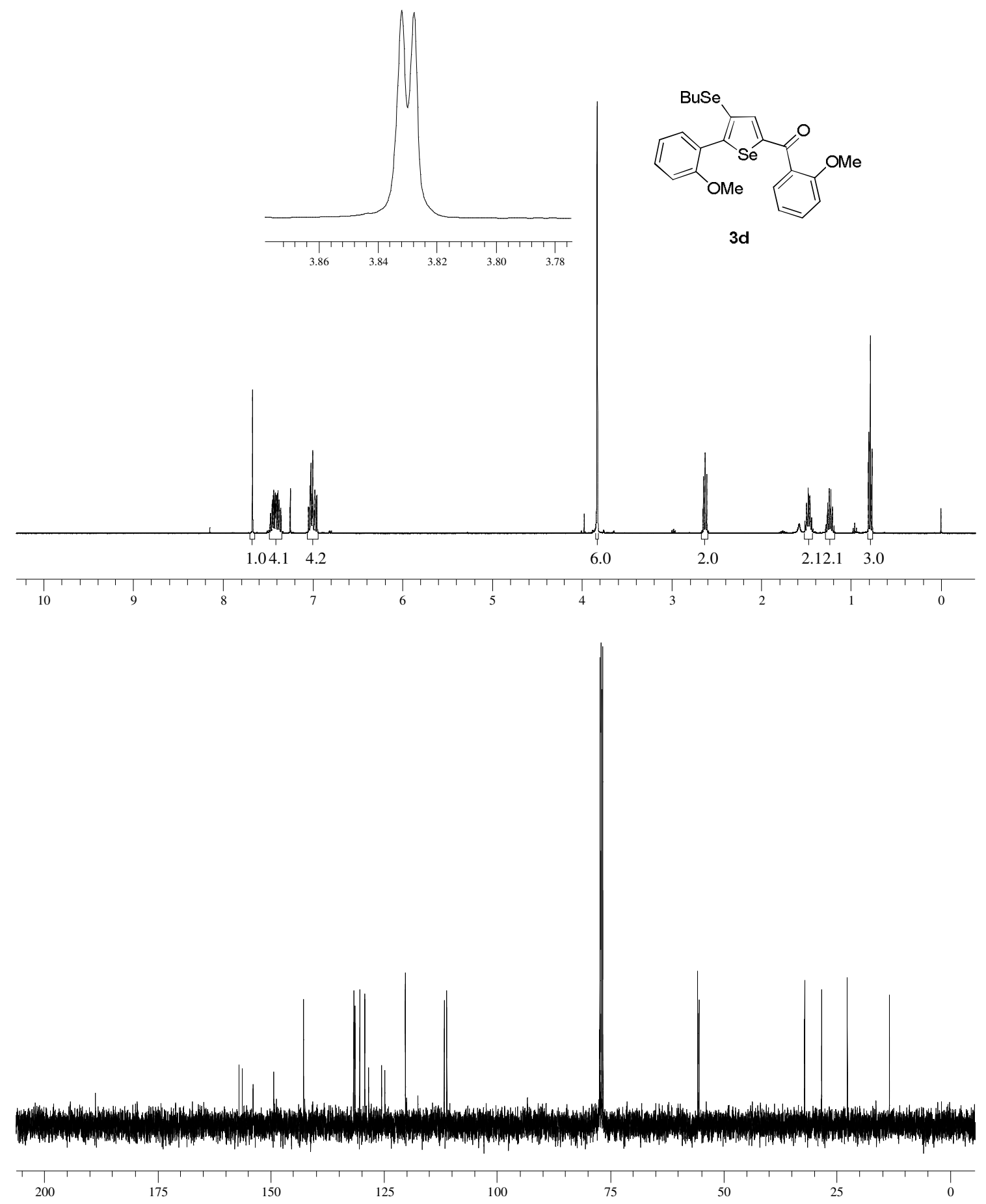

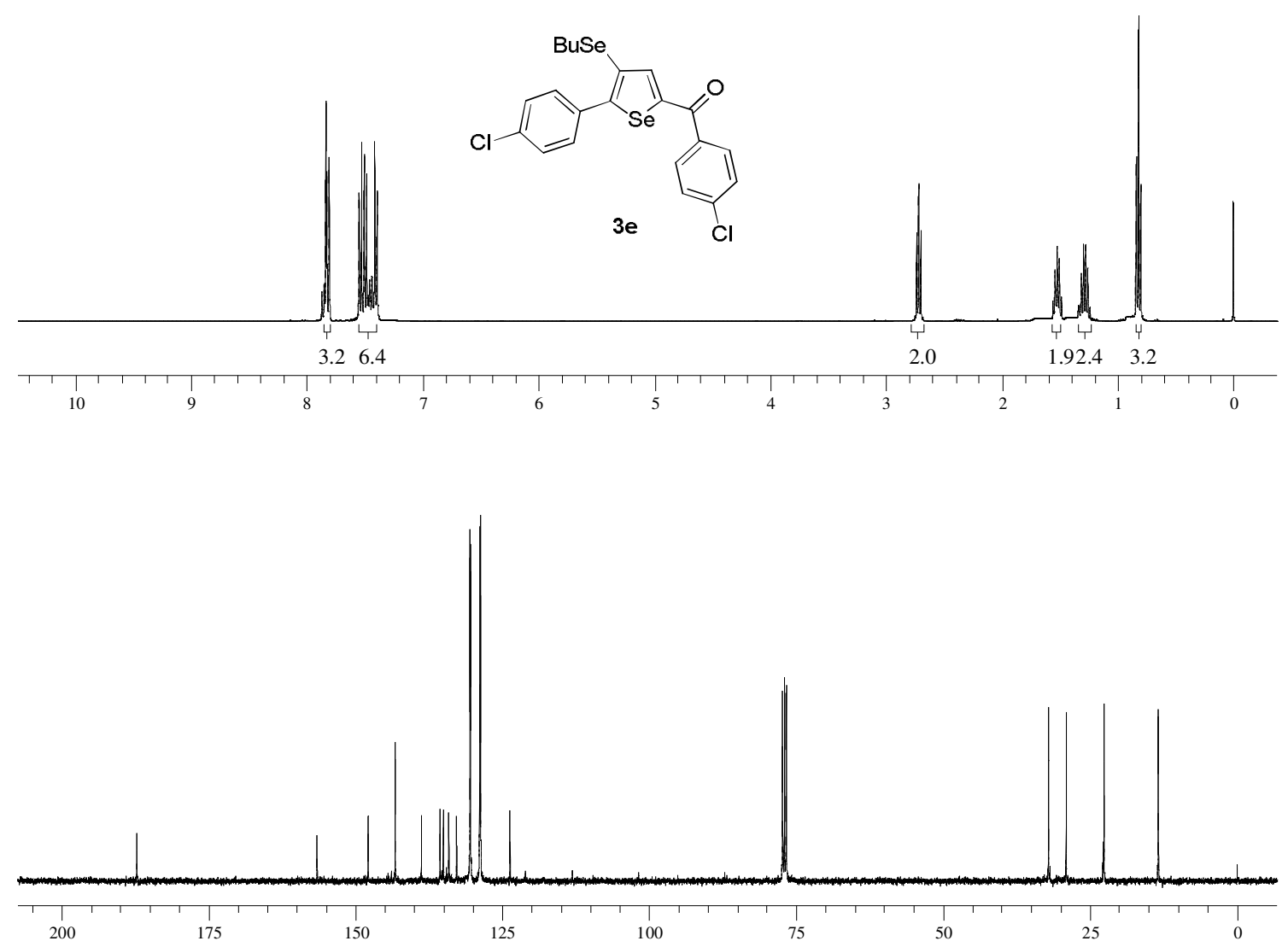


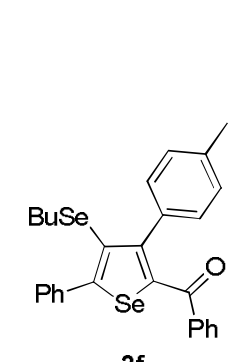

$3 f$
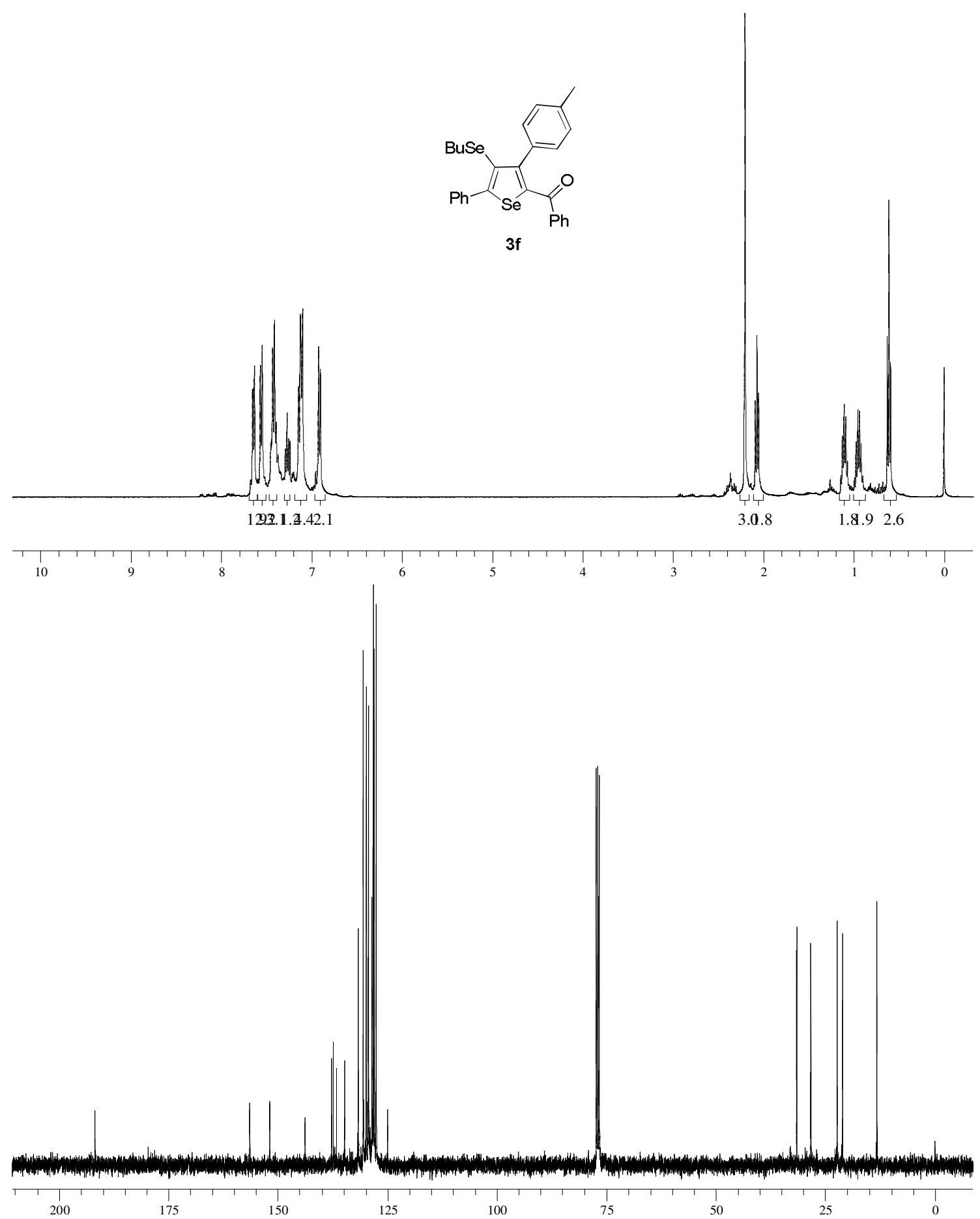

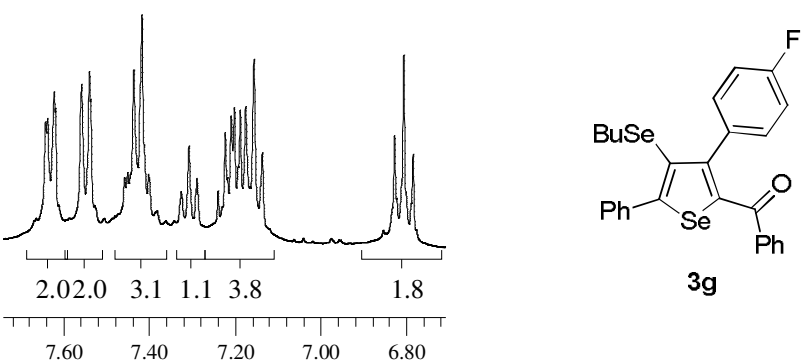

$\begin{array}{lllll}7.60 & 7.40 & 7.20 & 7.00 & 6.80\end{array}$
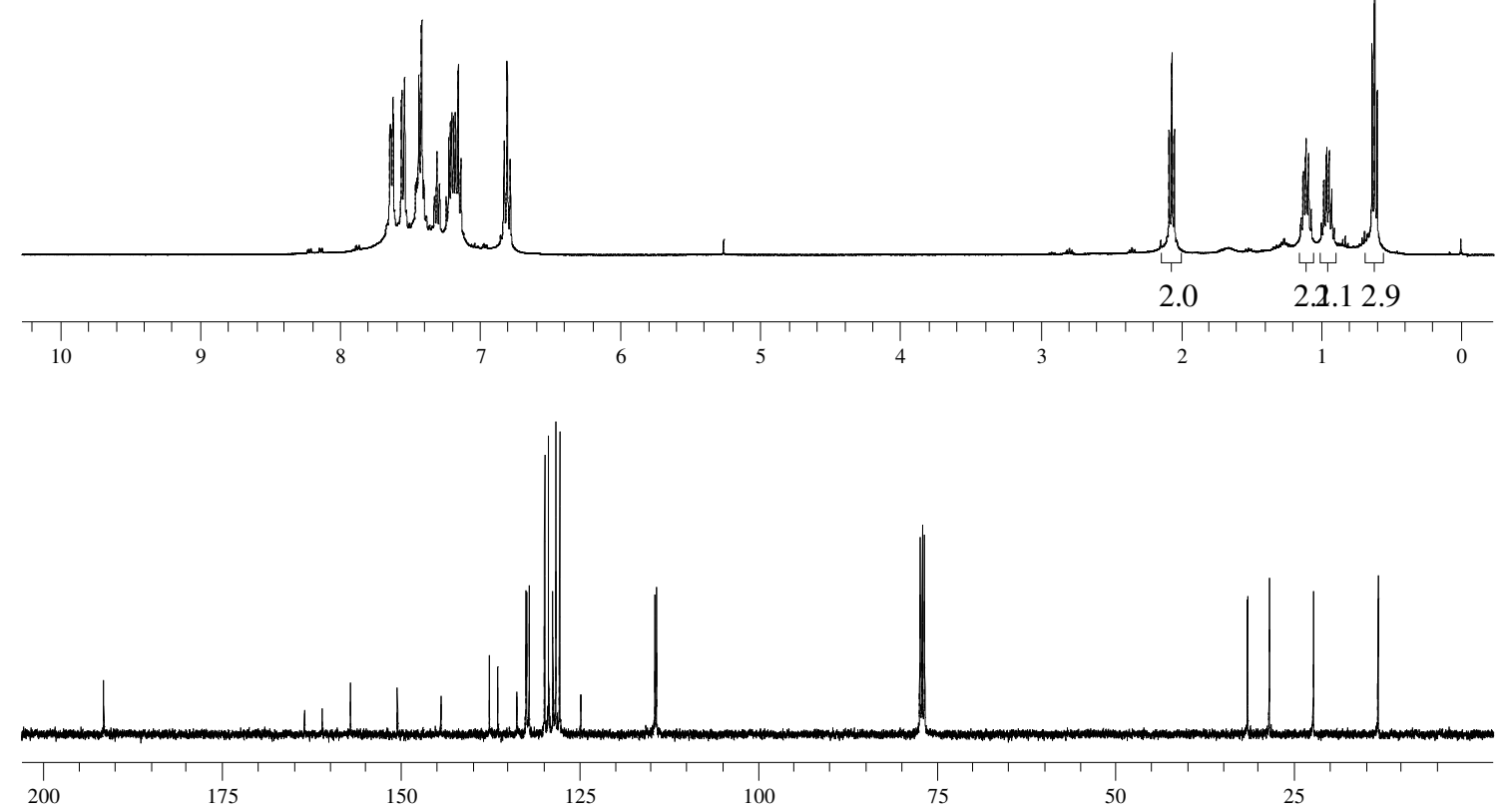

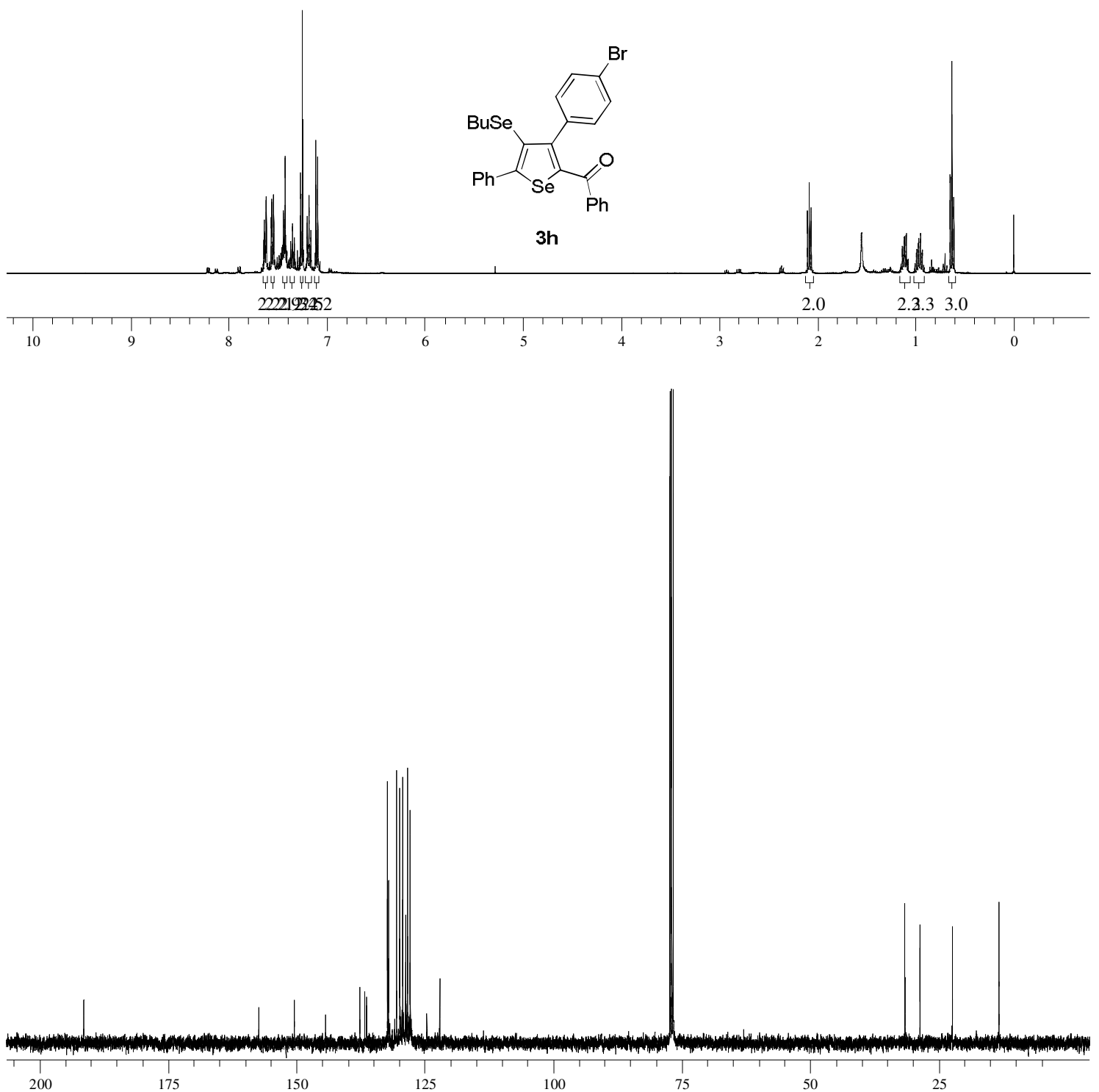

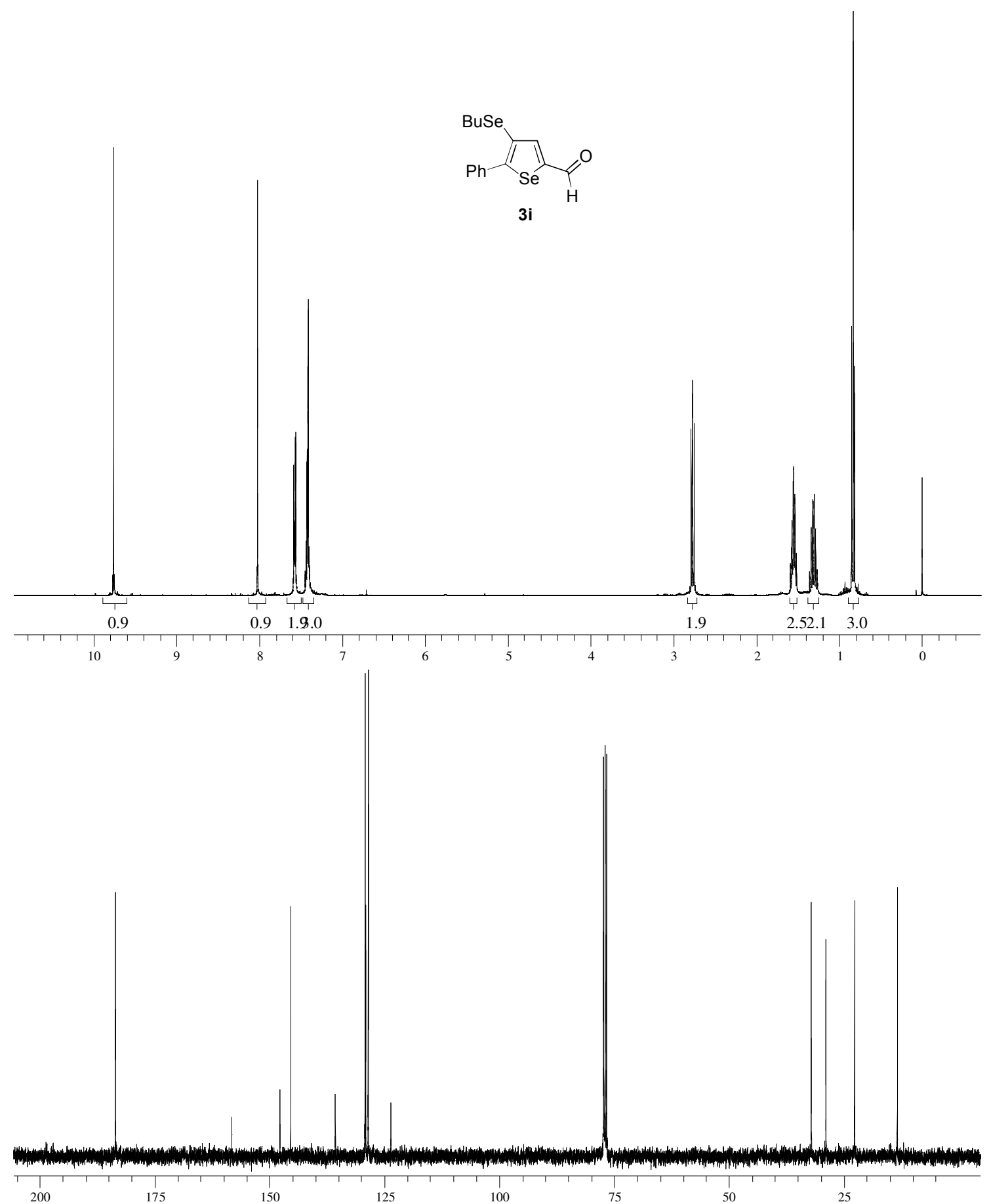

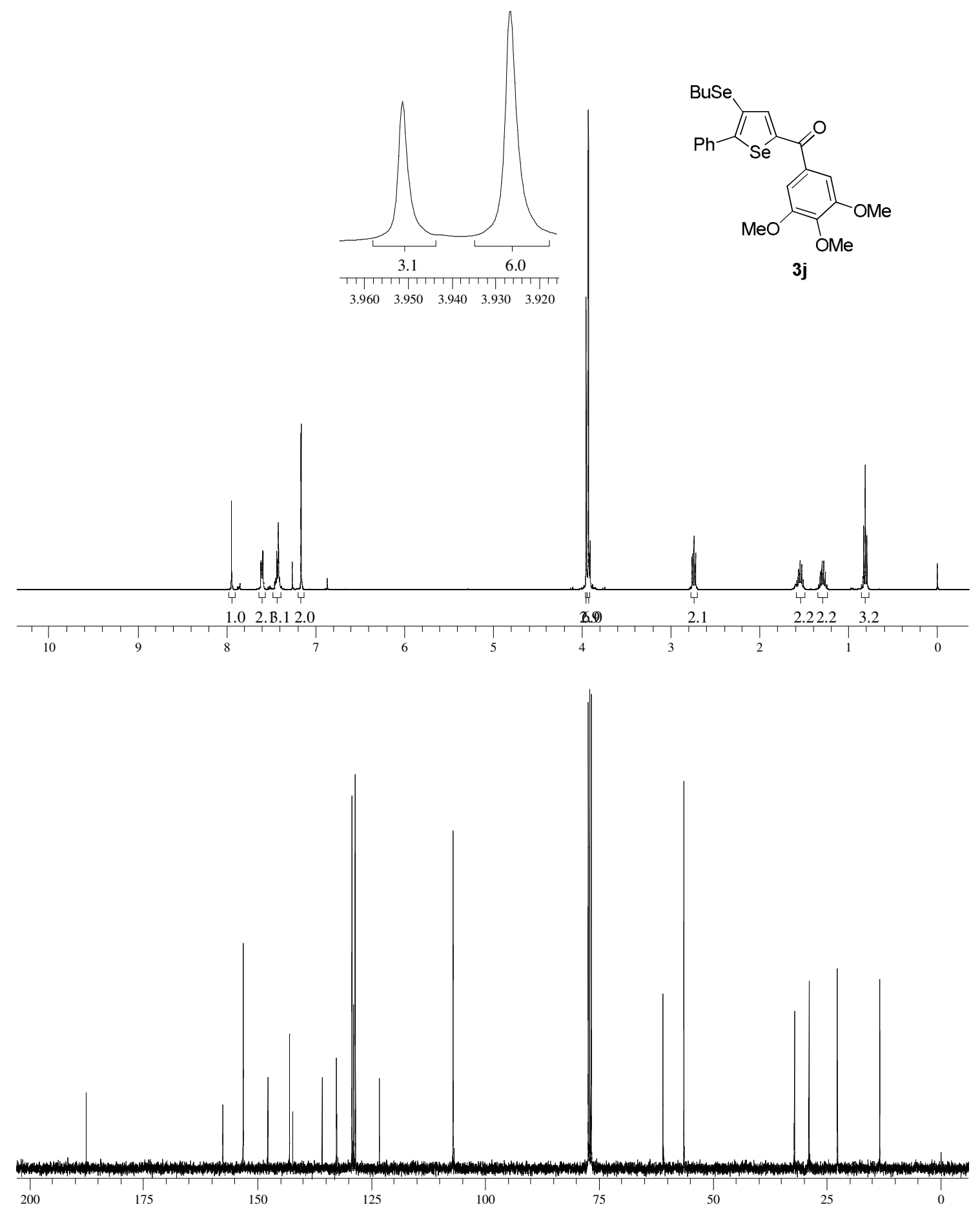

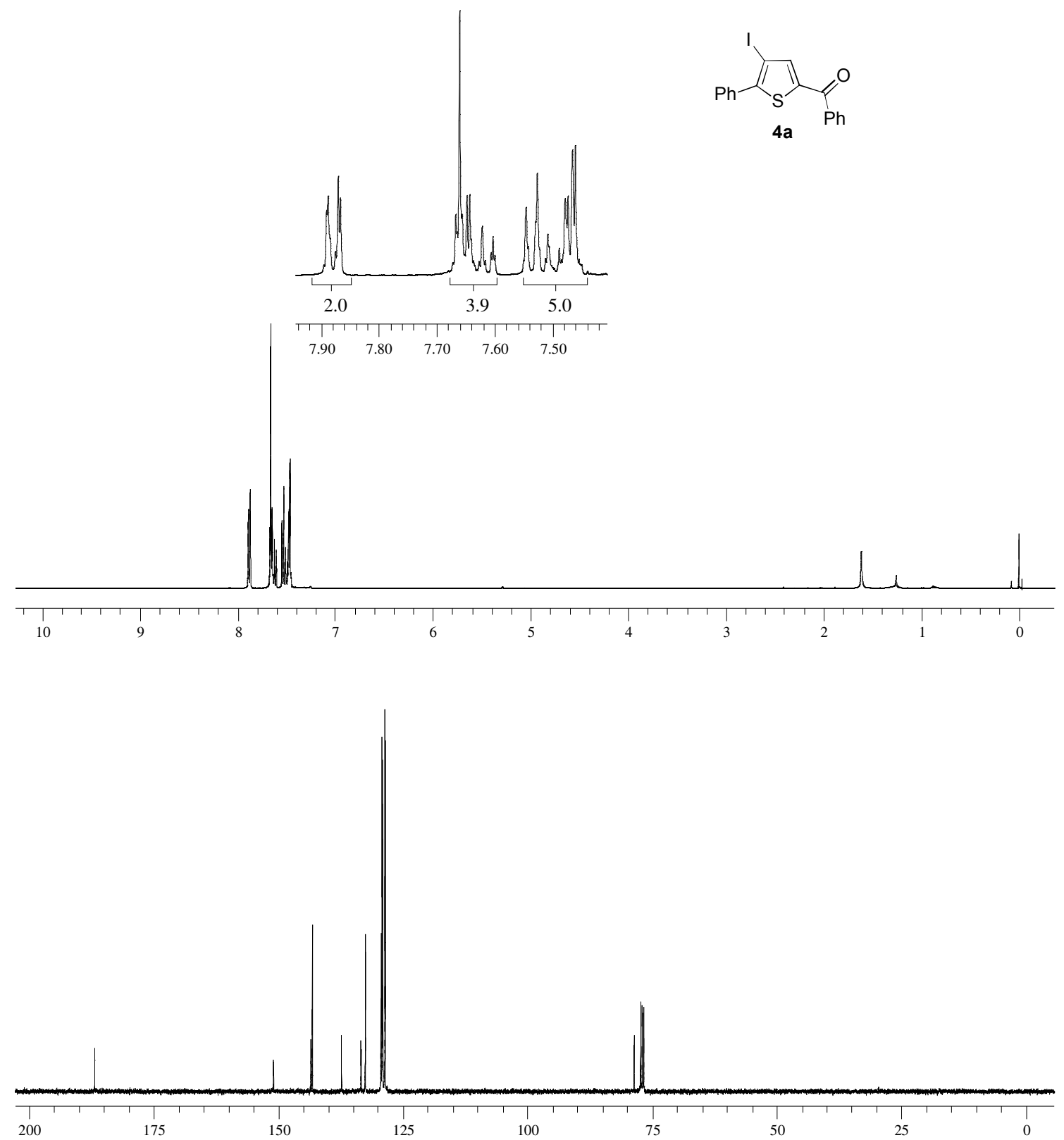

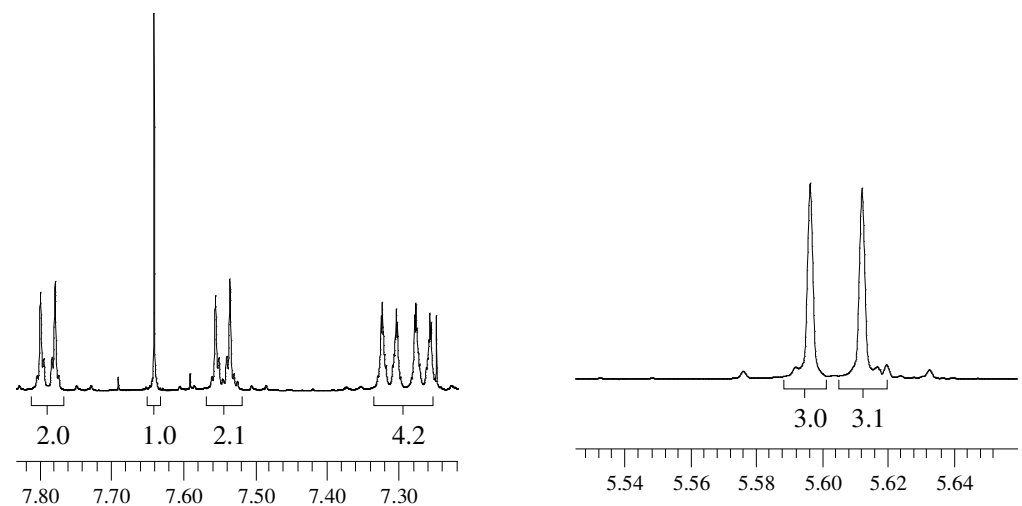

$\begin{array}{llllll}5.54 & 5.56 & 5.58 & 5.60 & 5.62 & 5.64\end{array}$
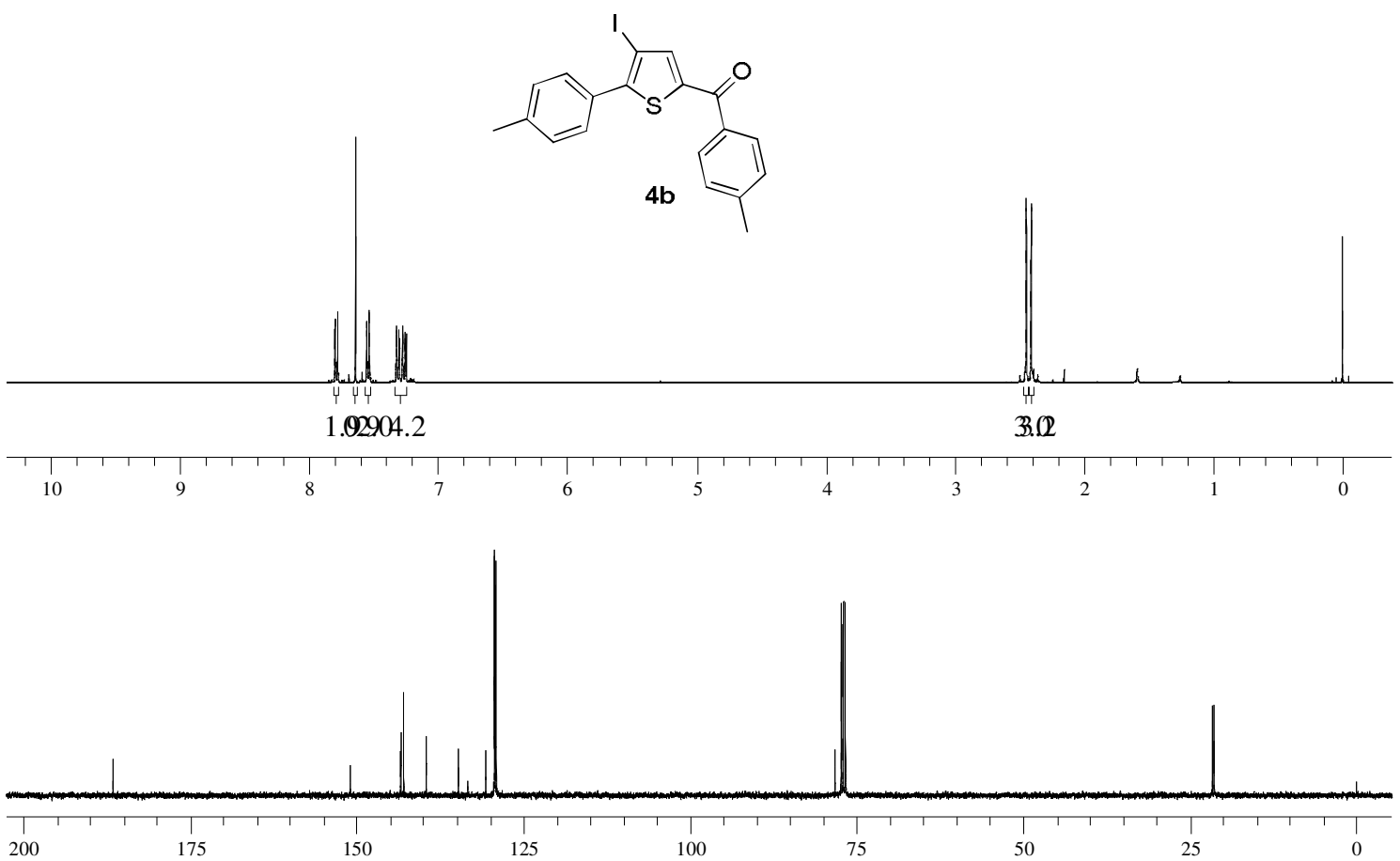


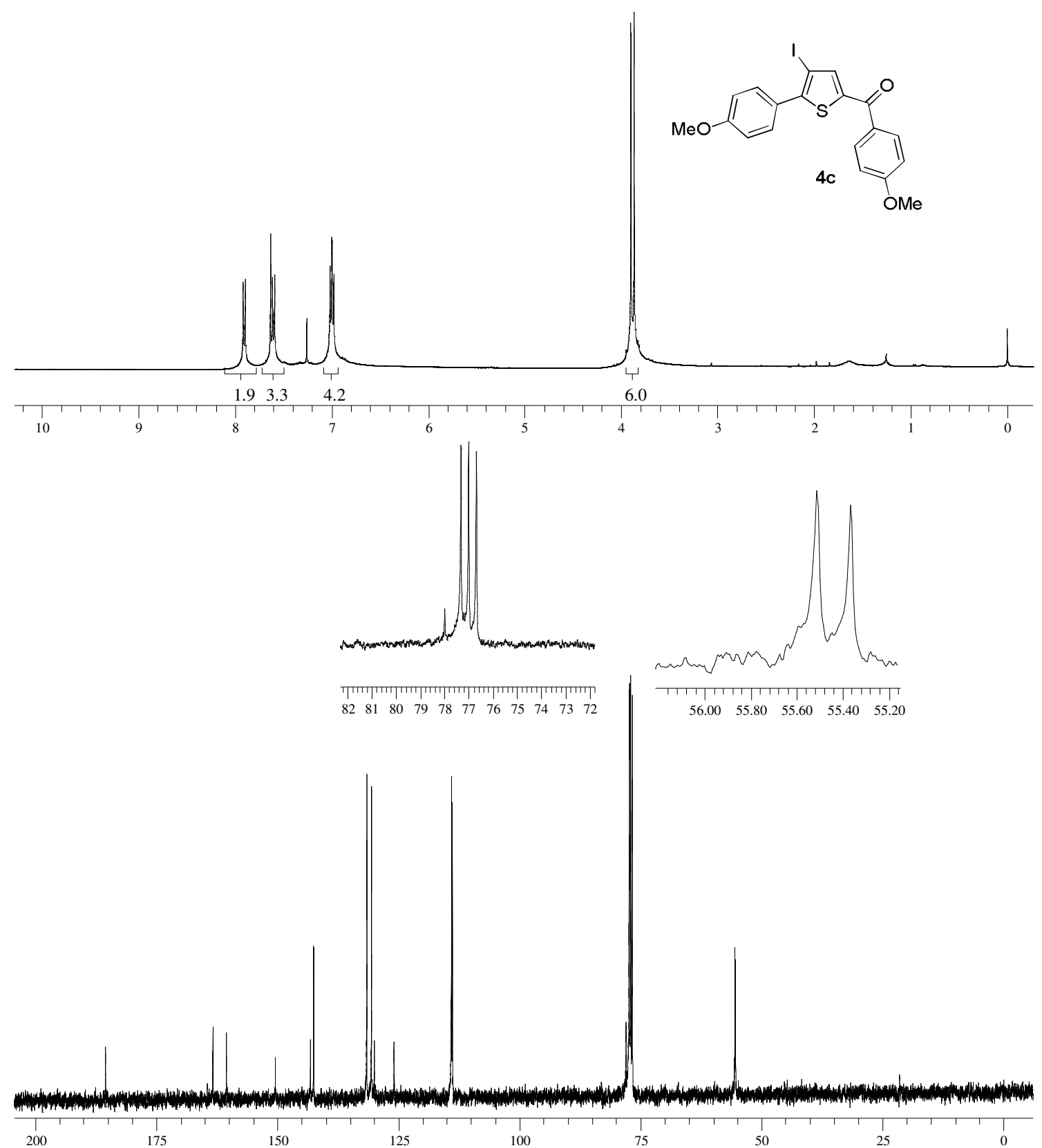



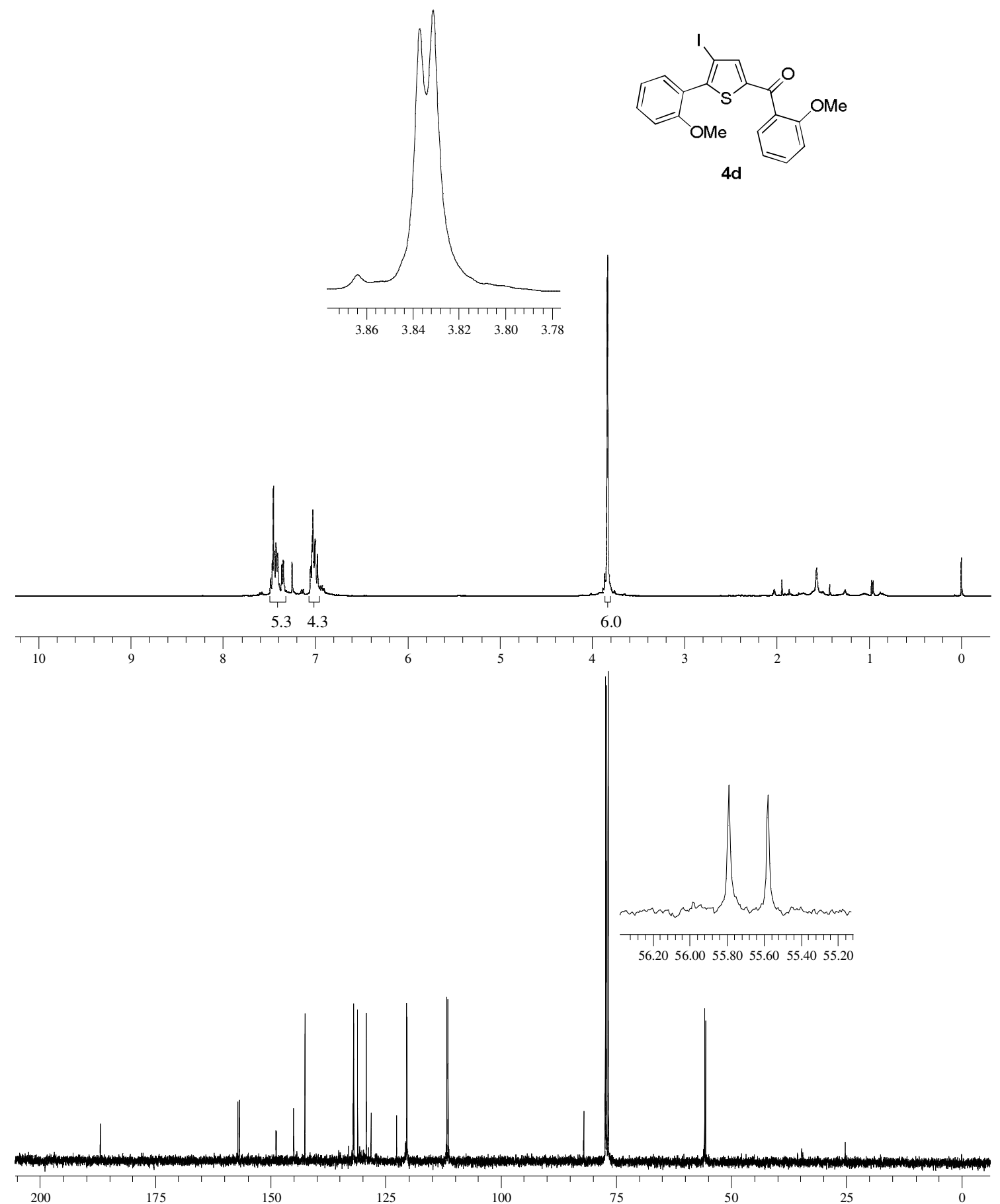

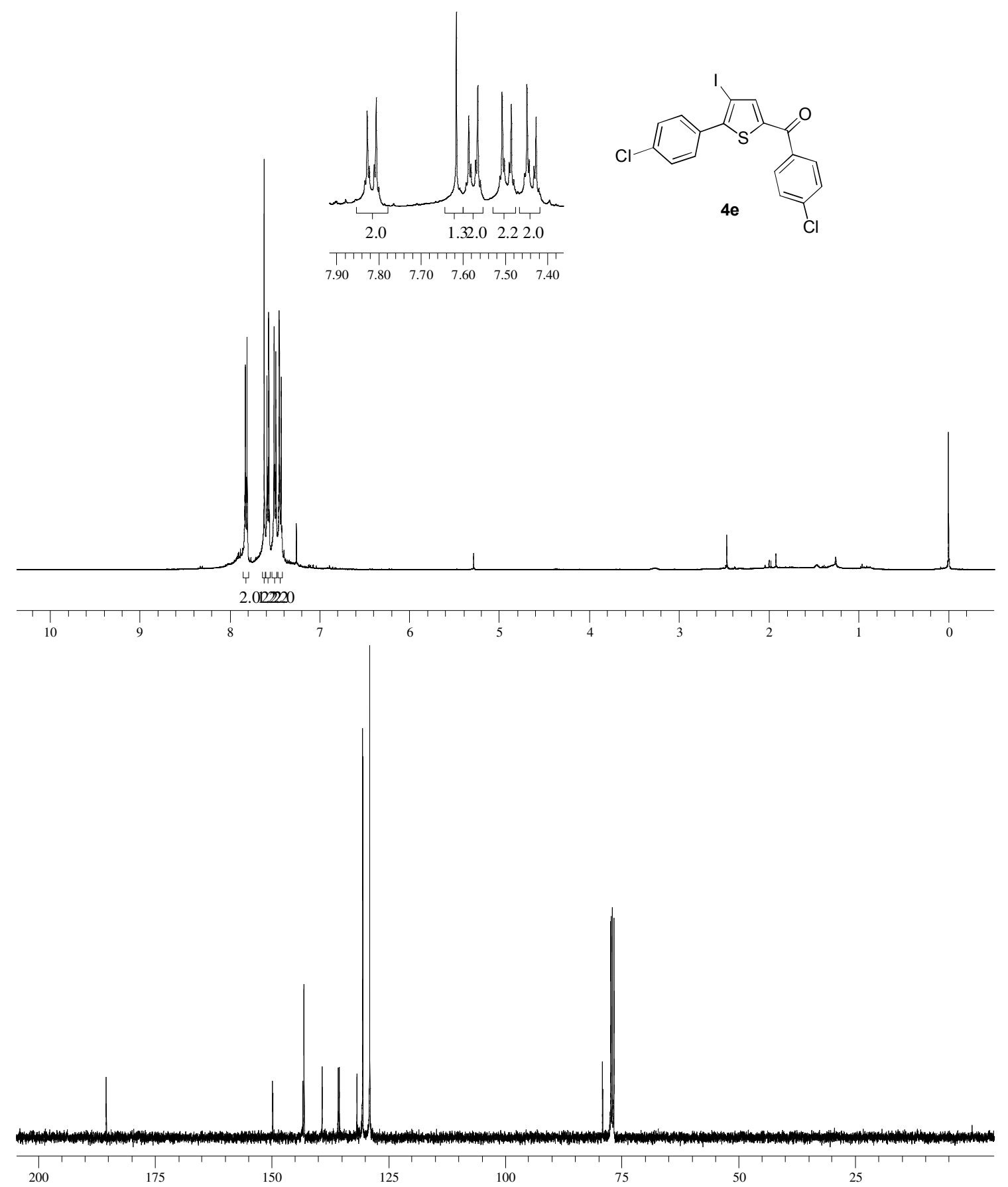

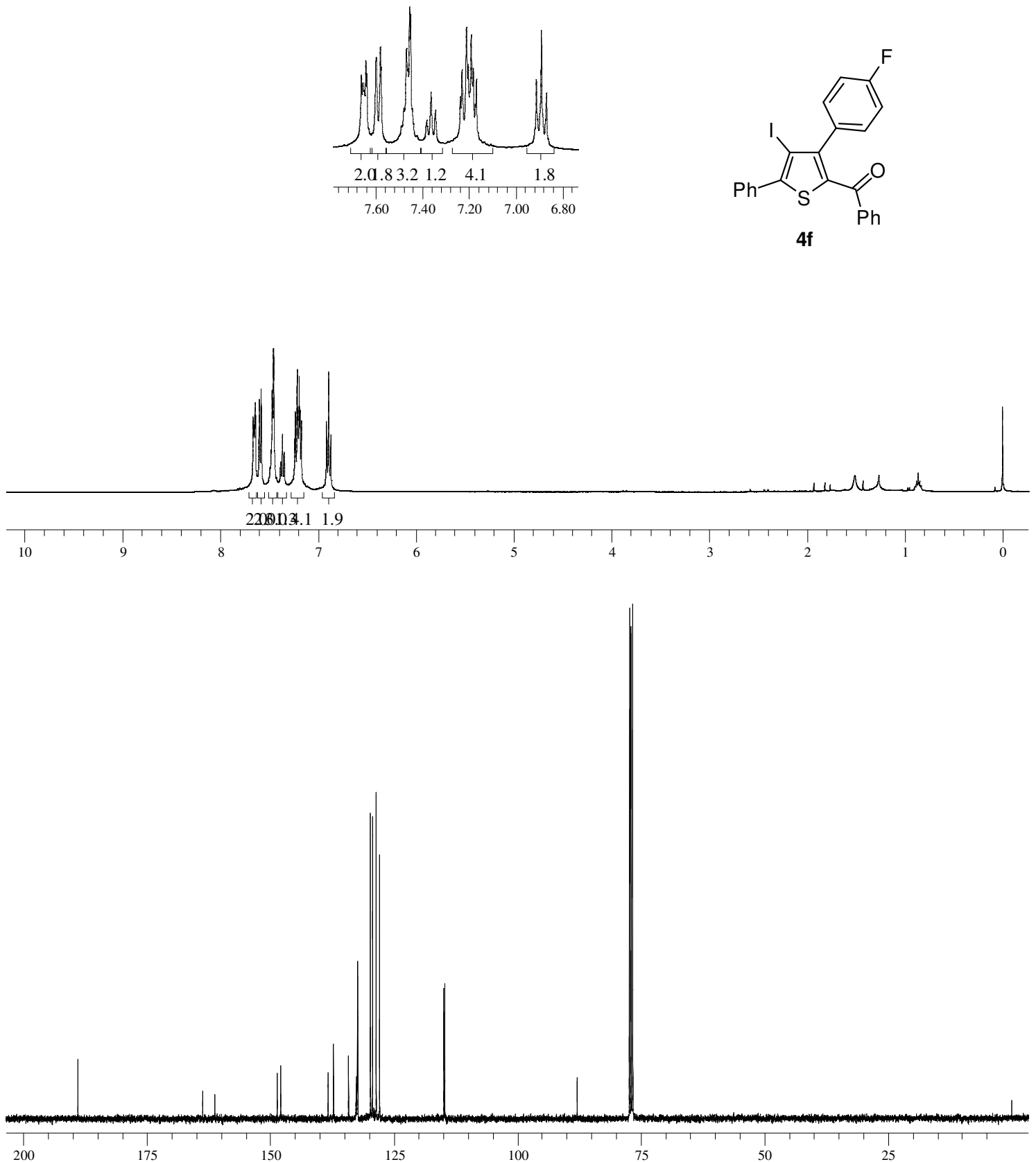

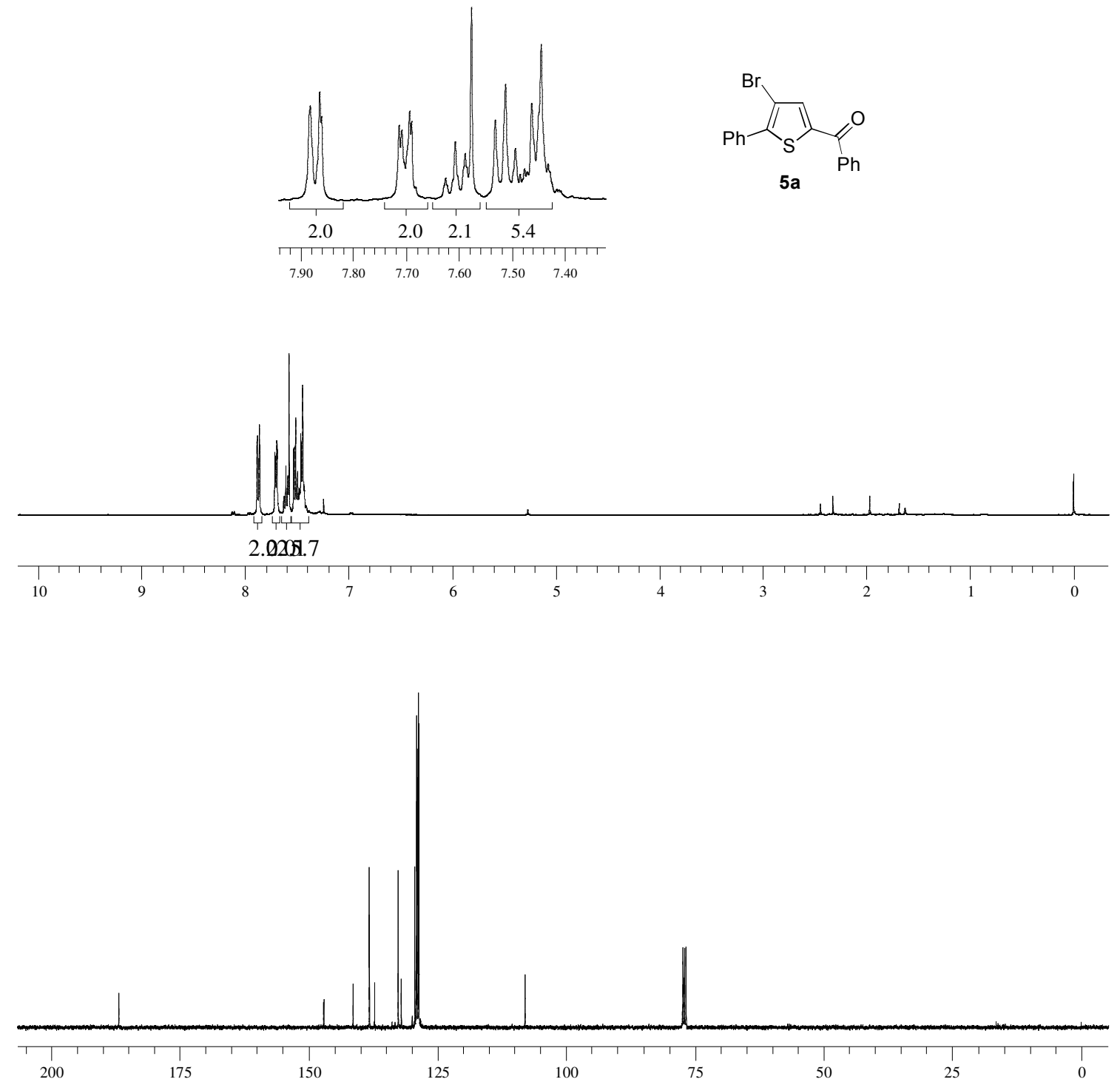

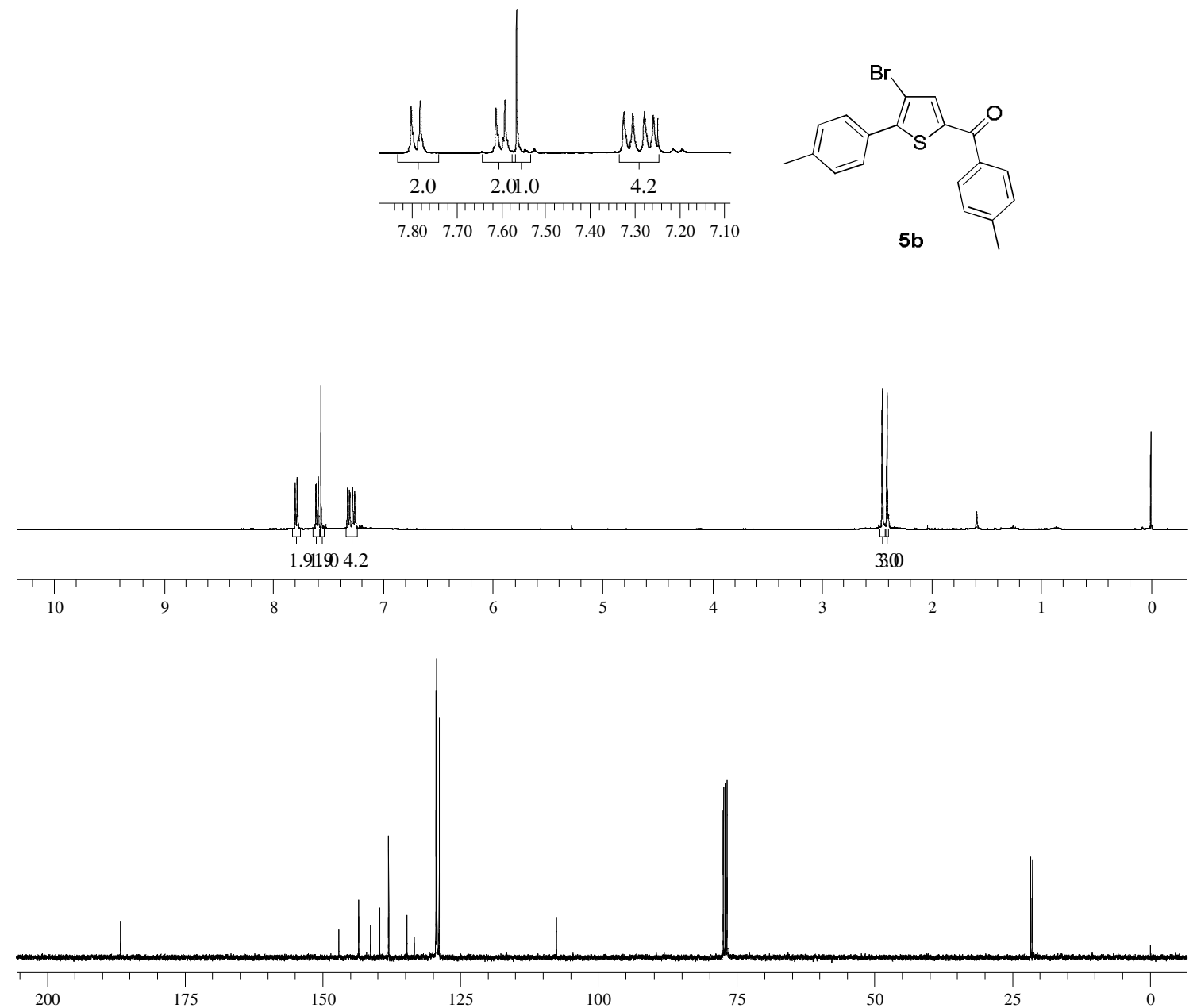

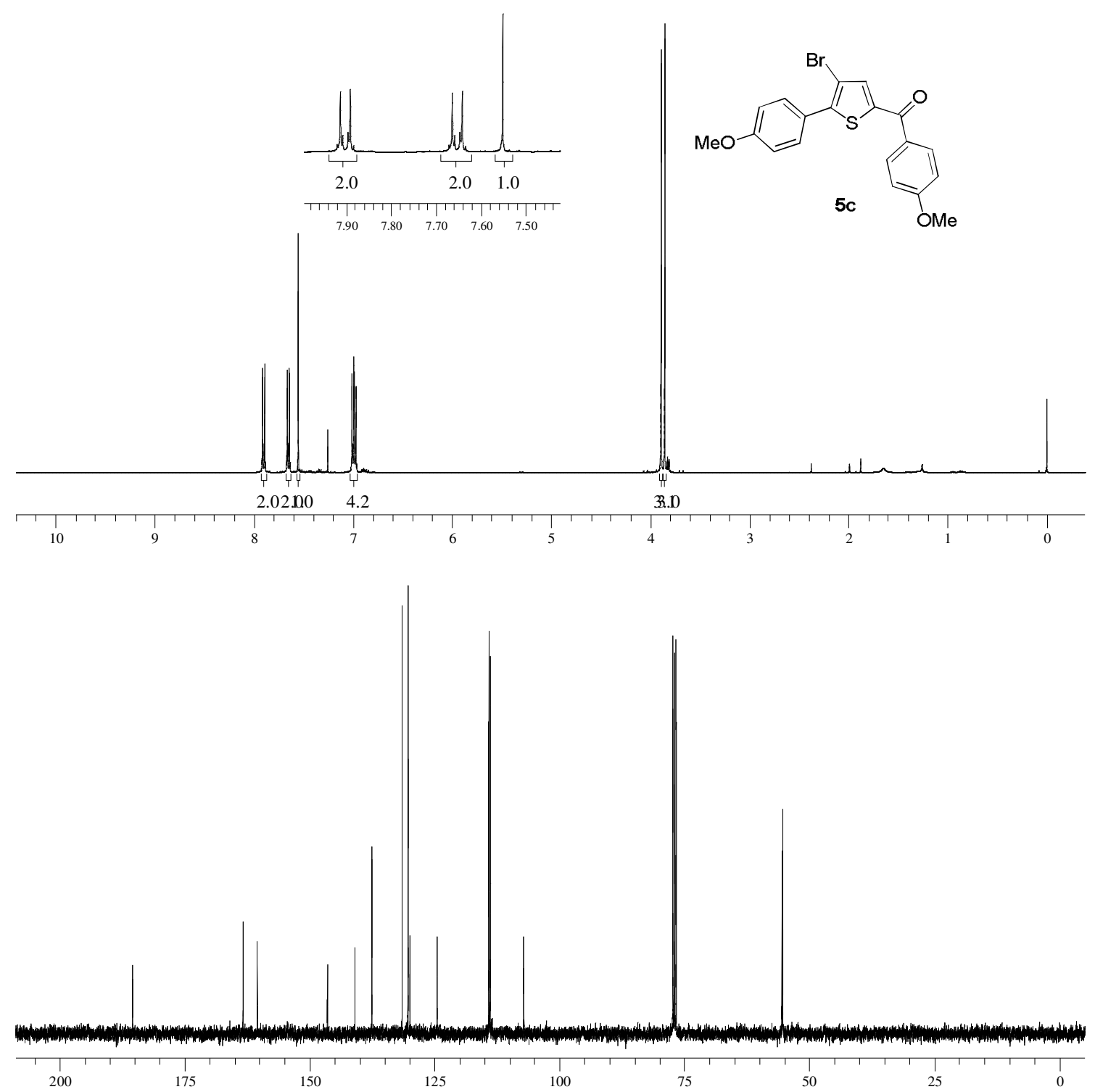

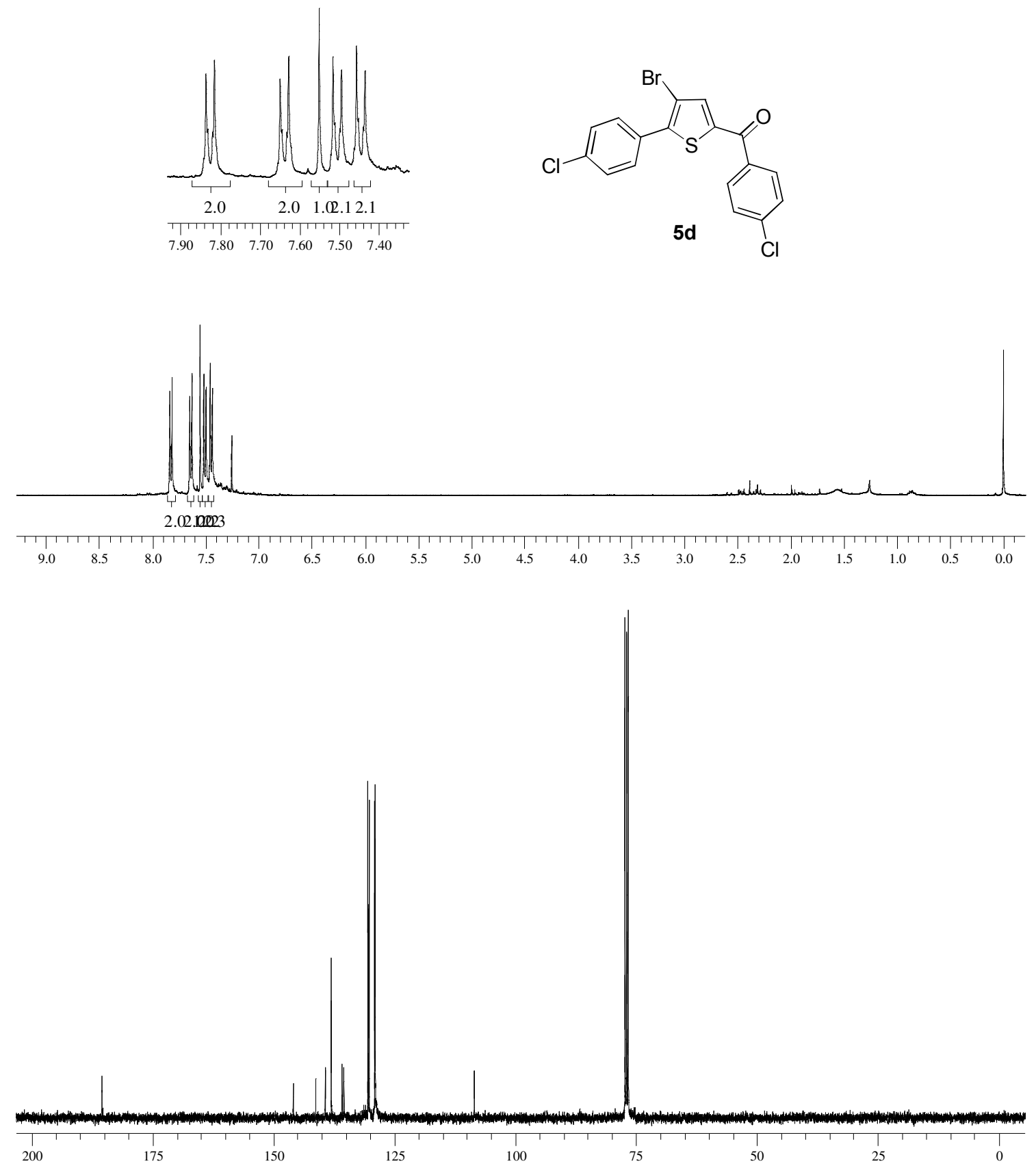

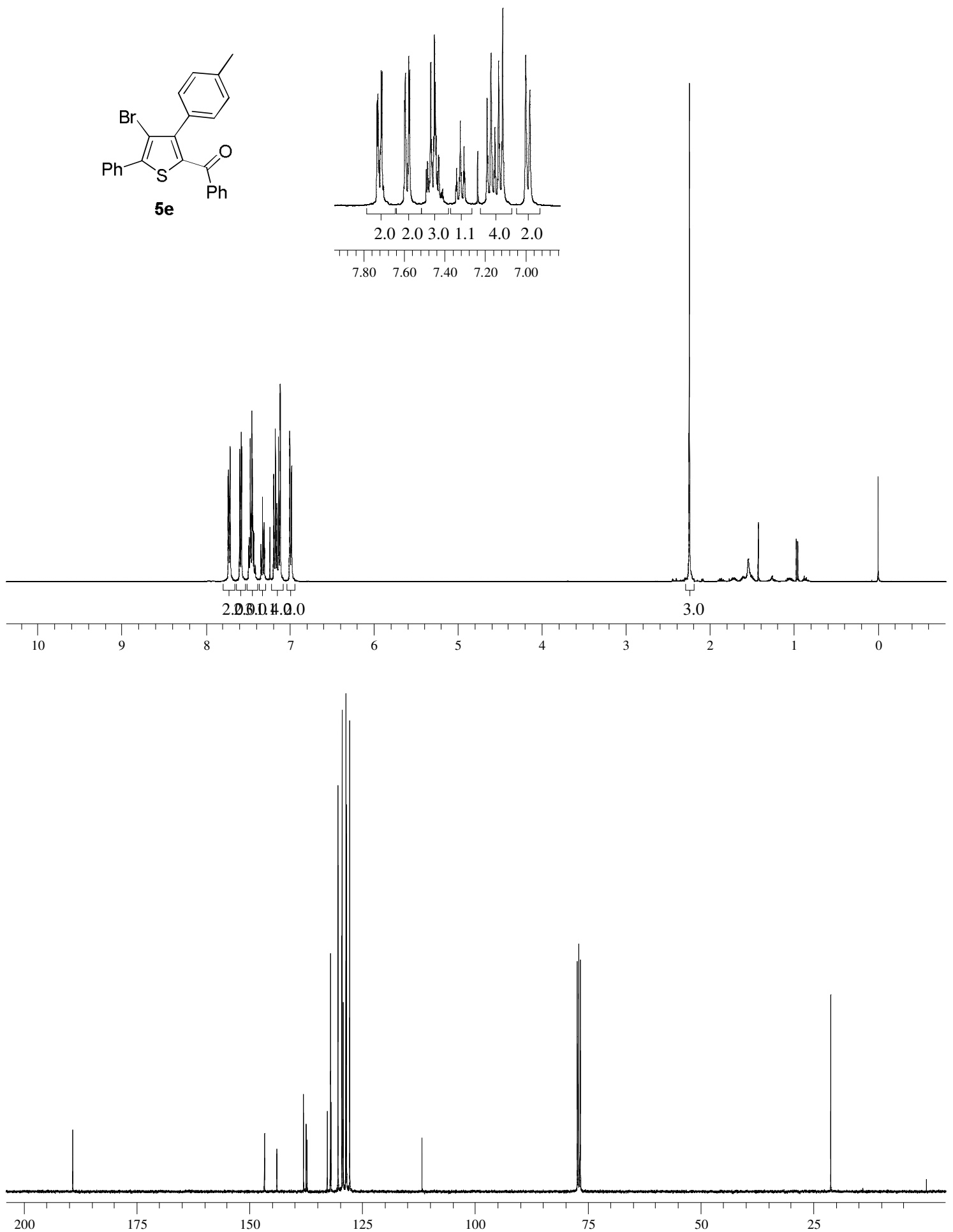

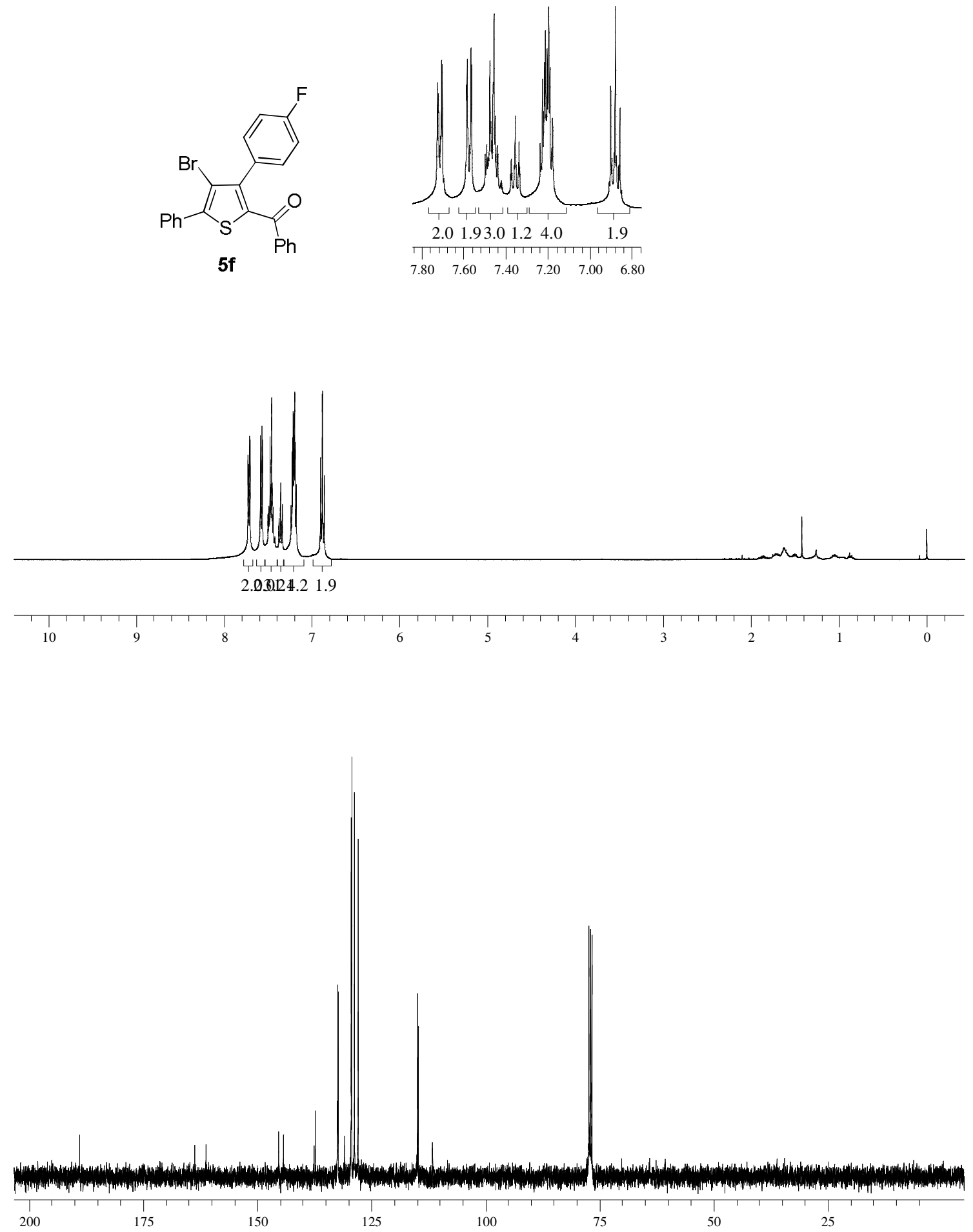


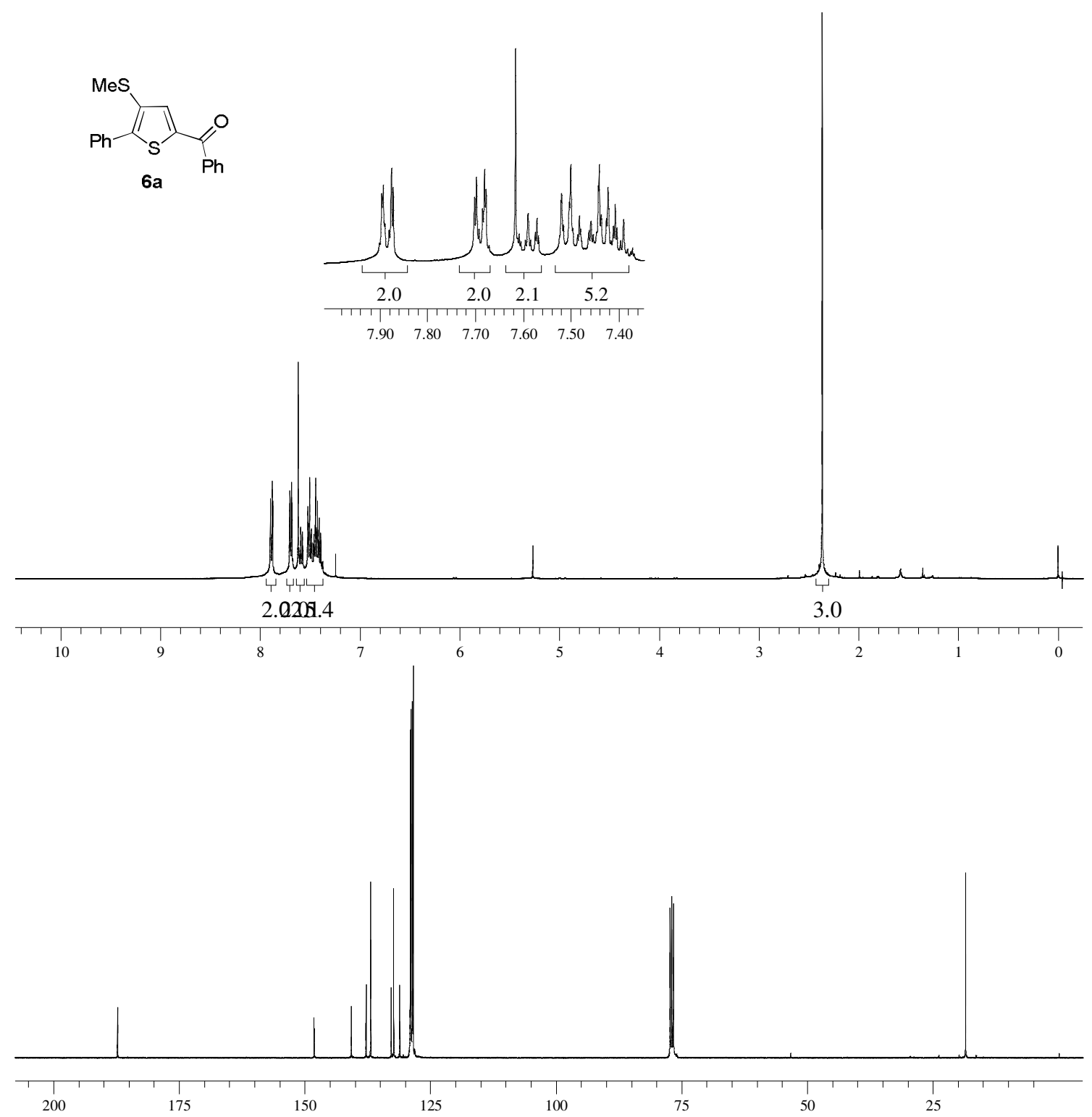



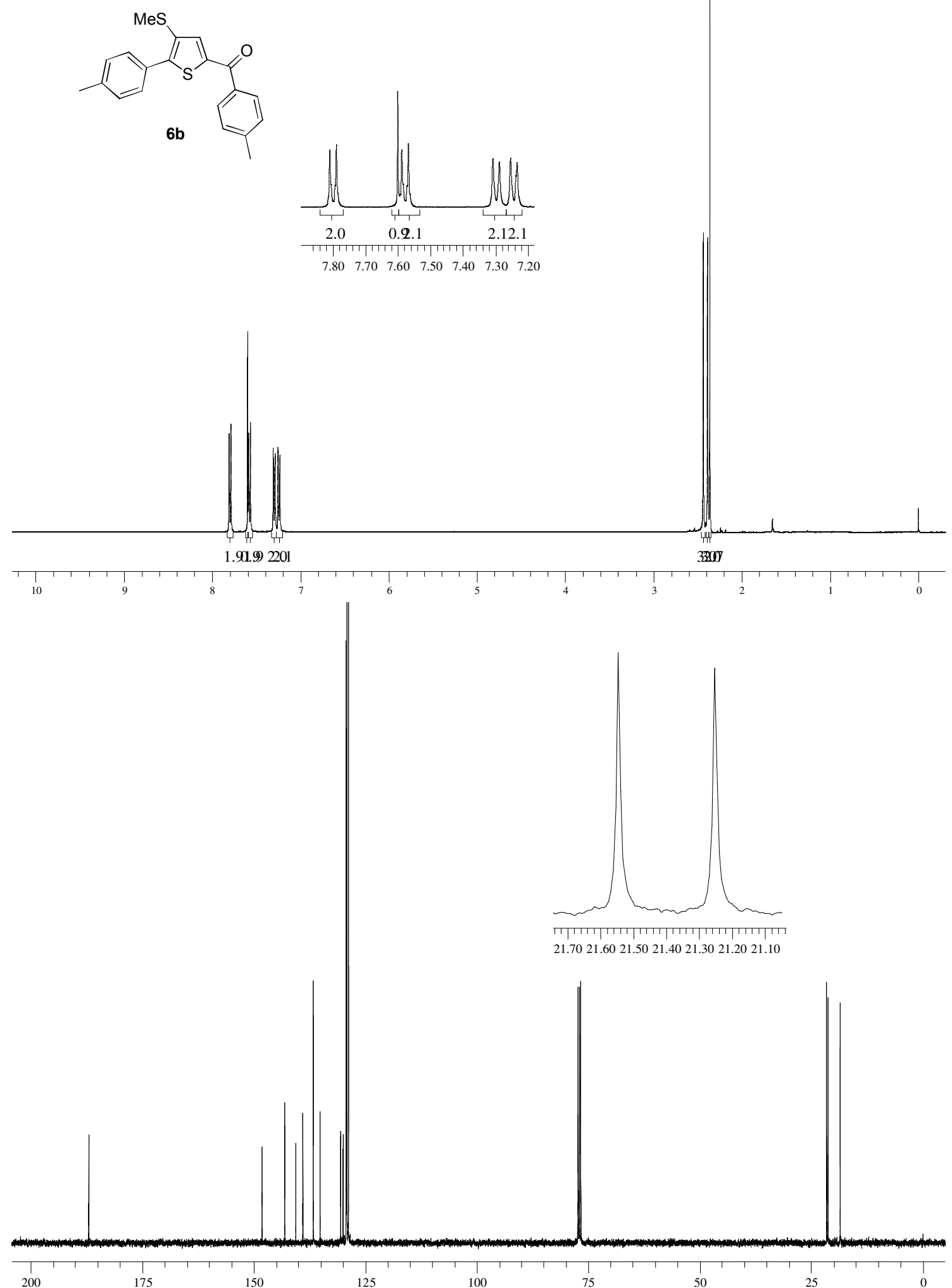

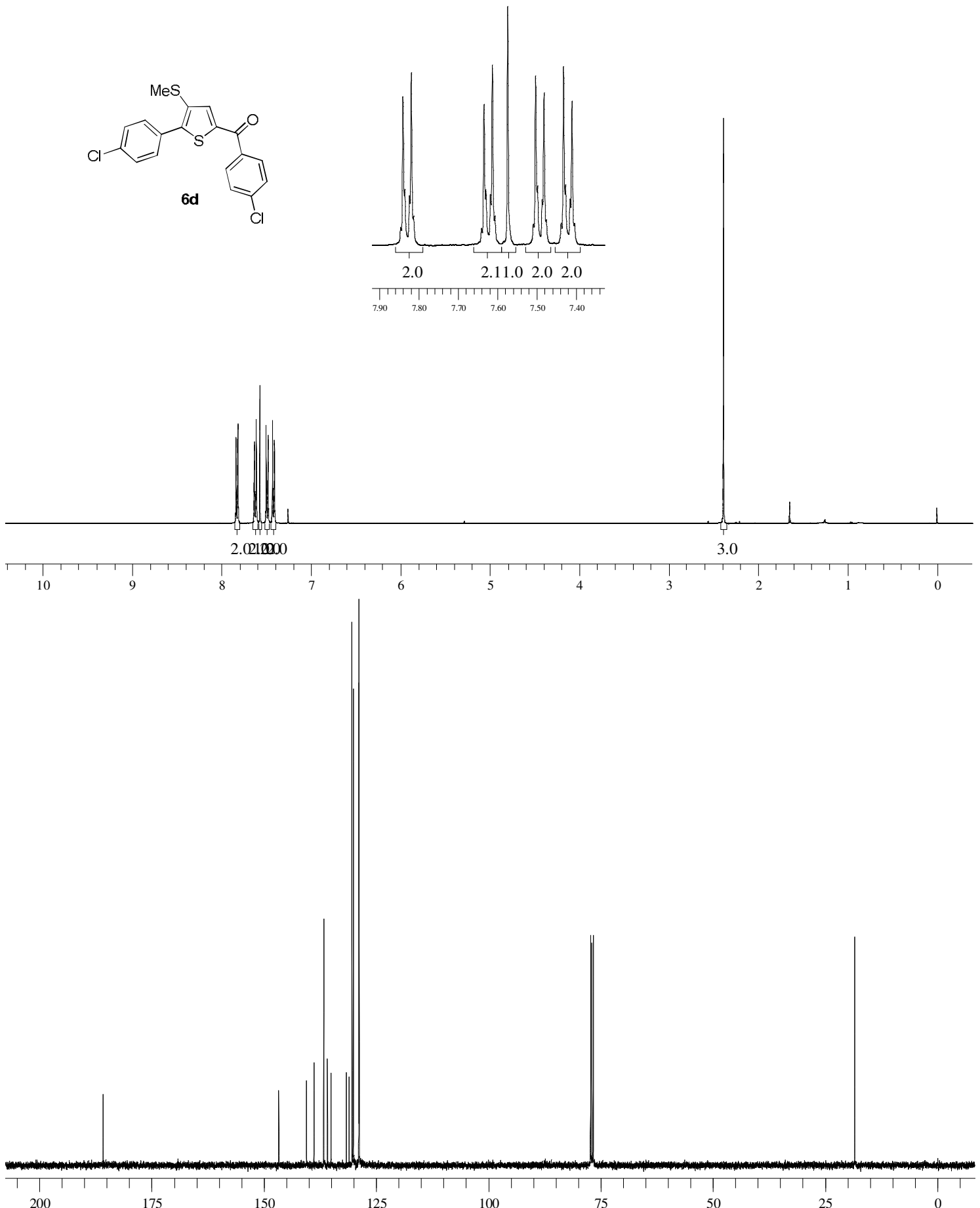


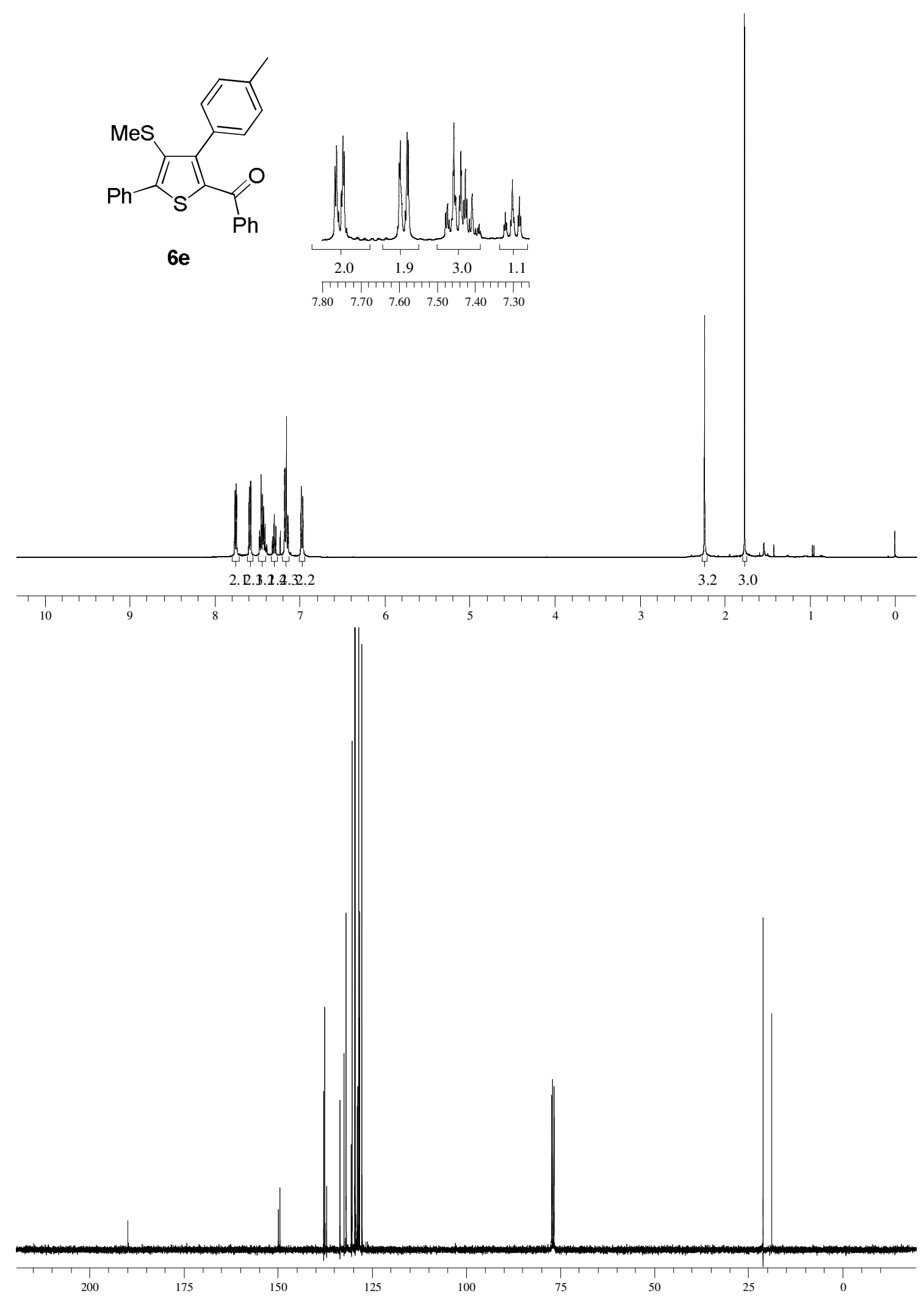



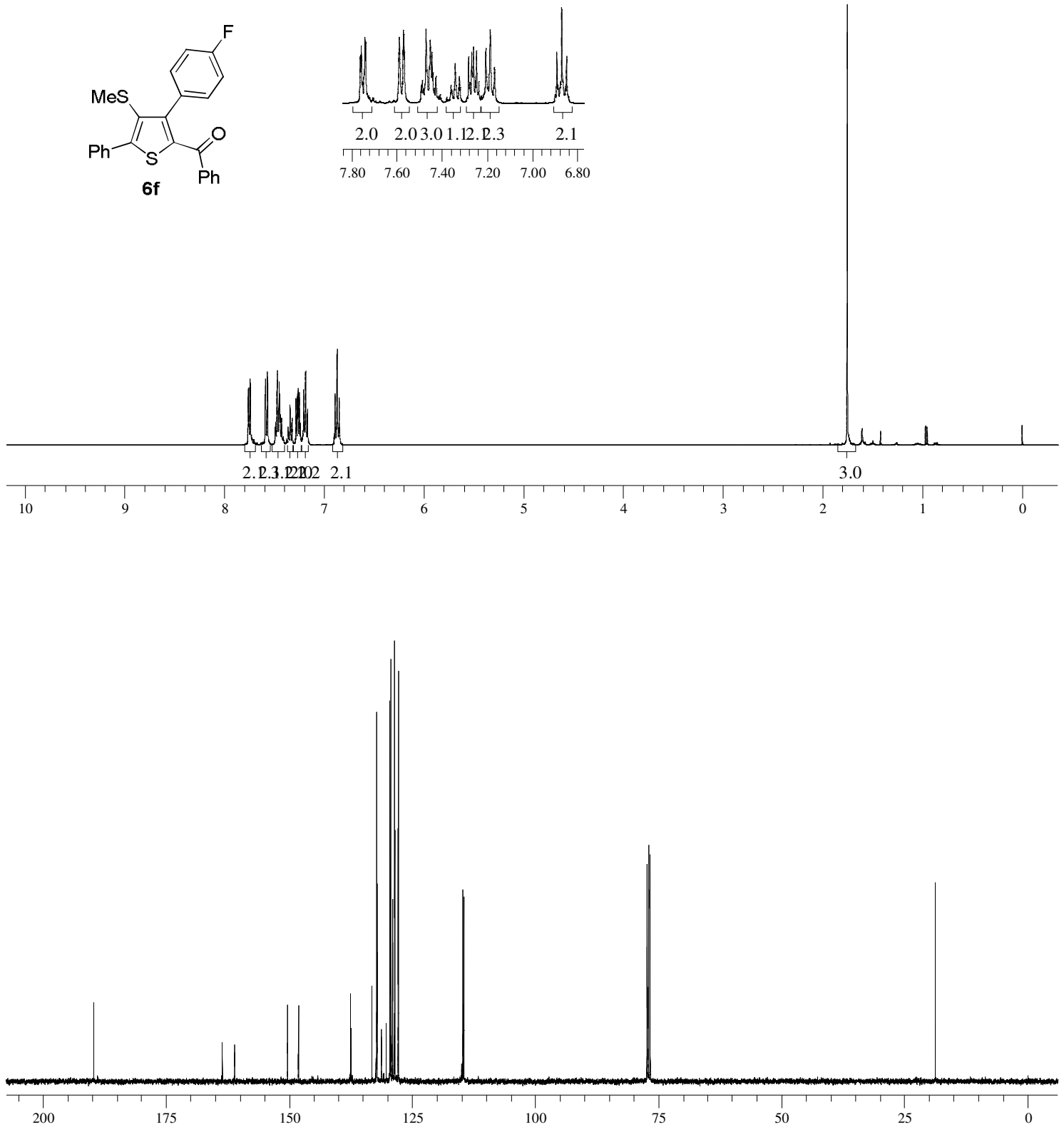

38 


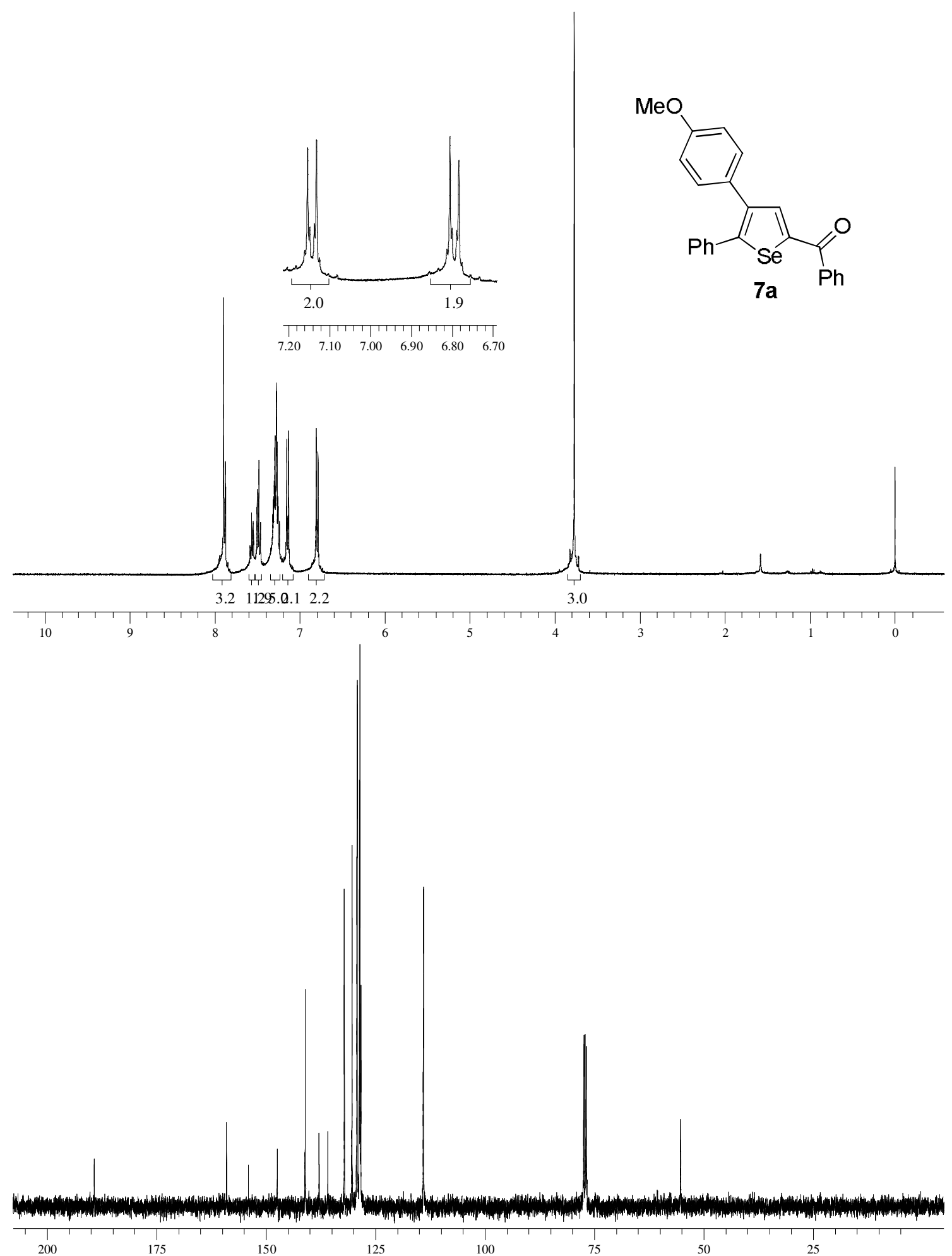




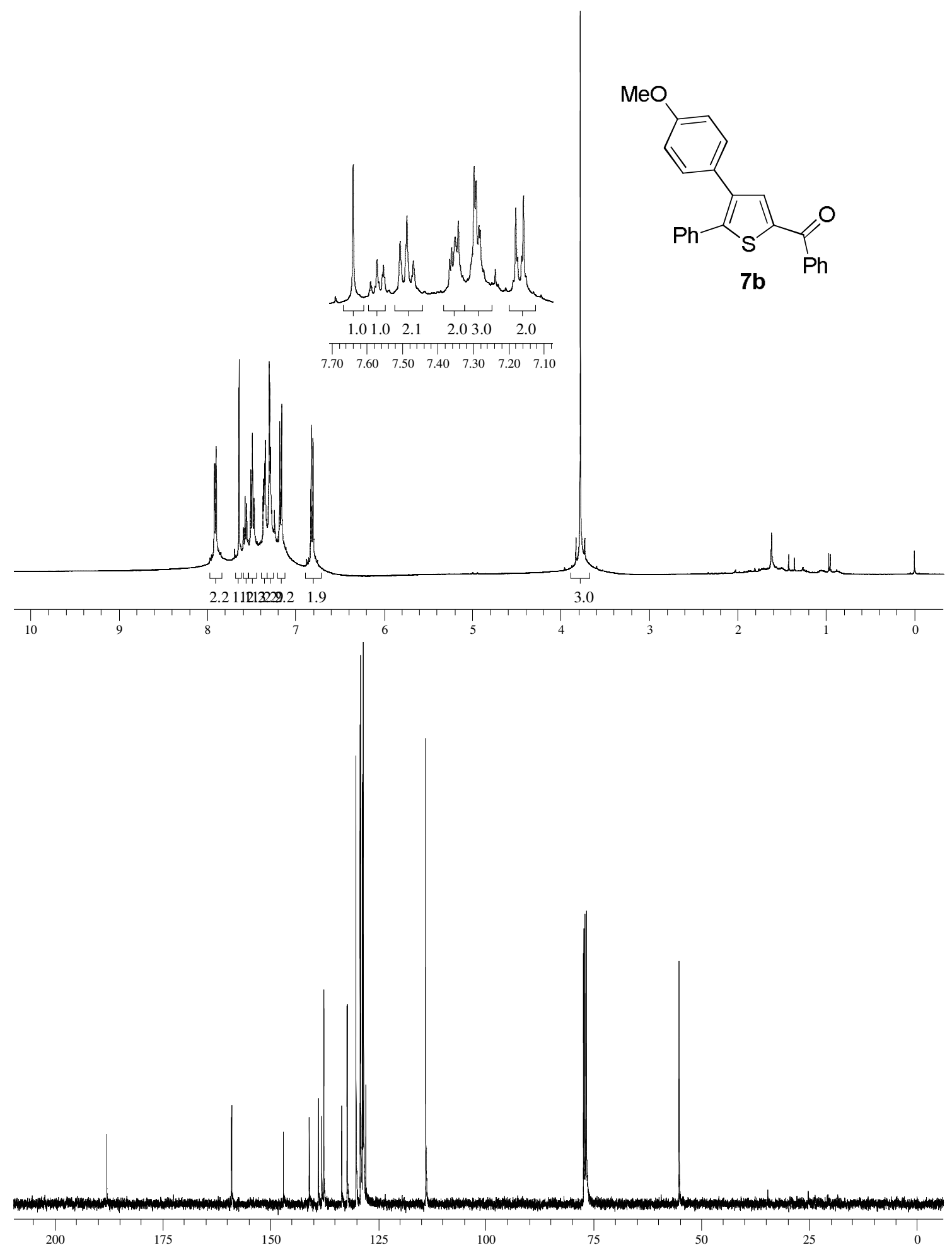




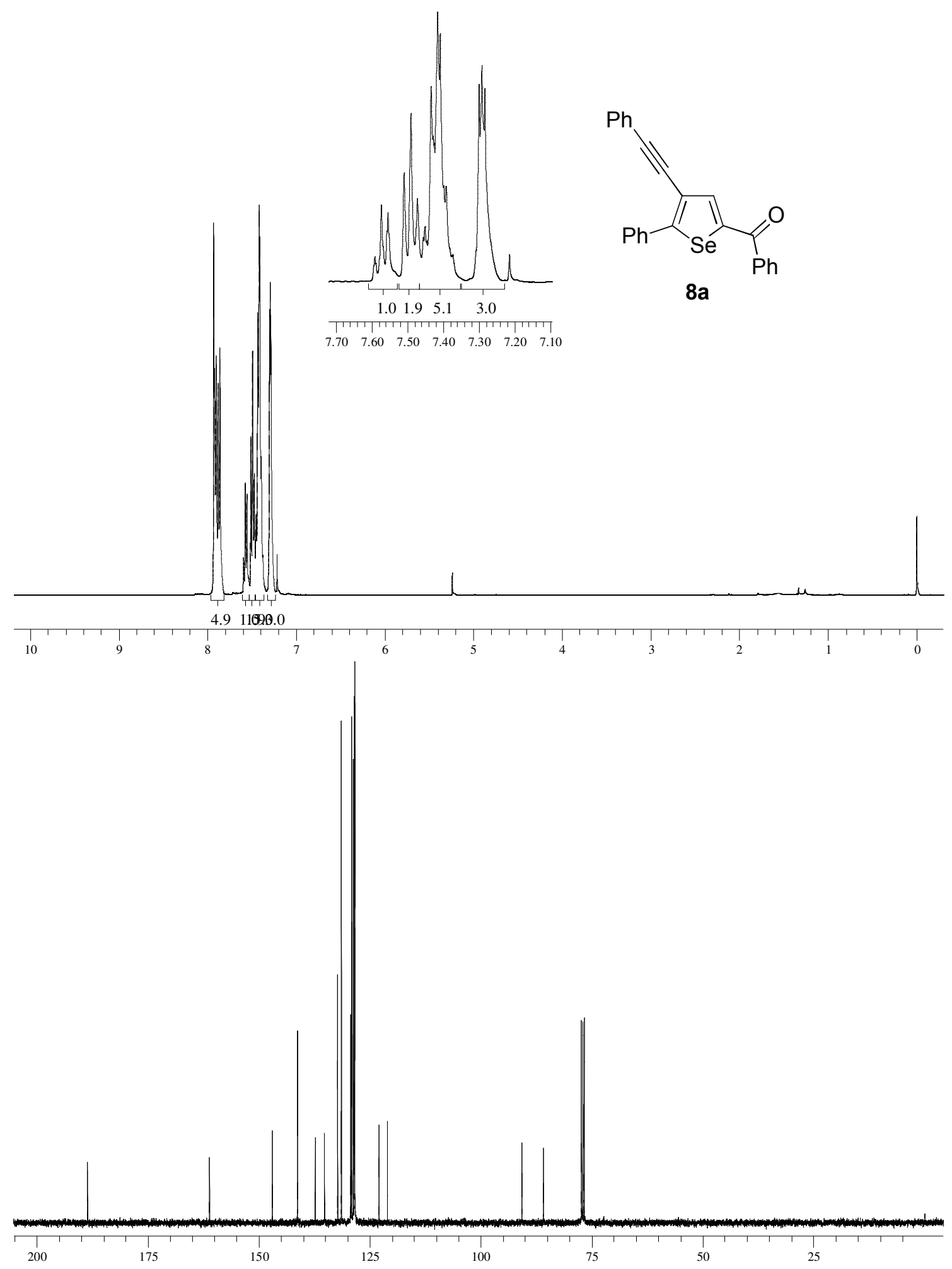



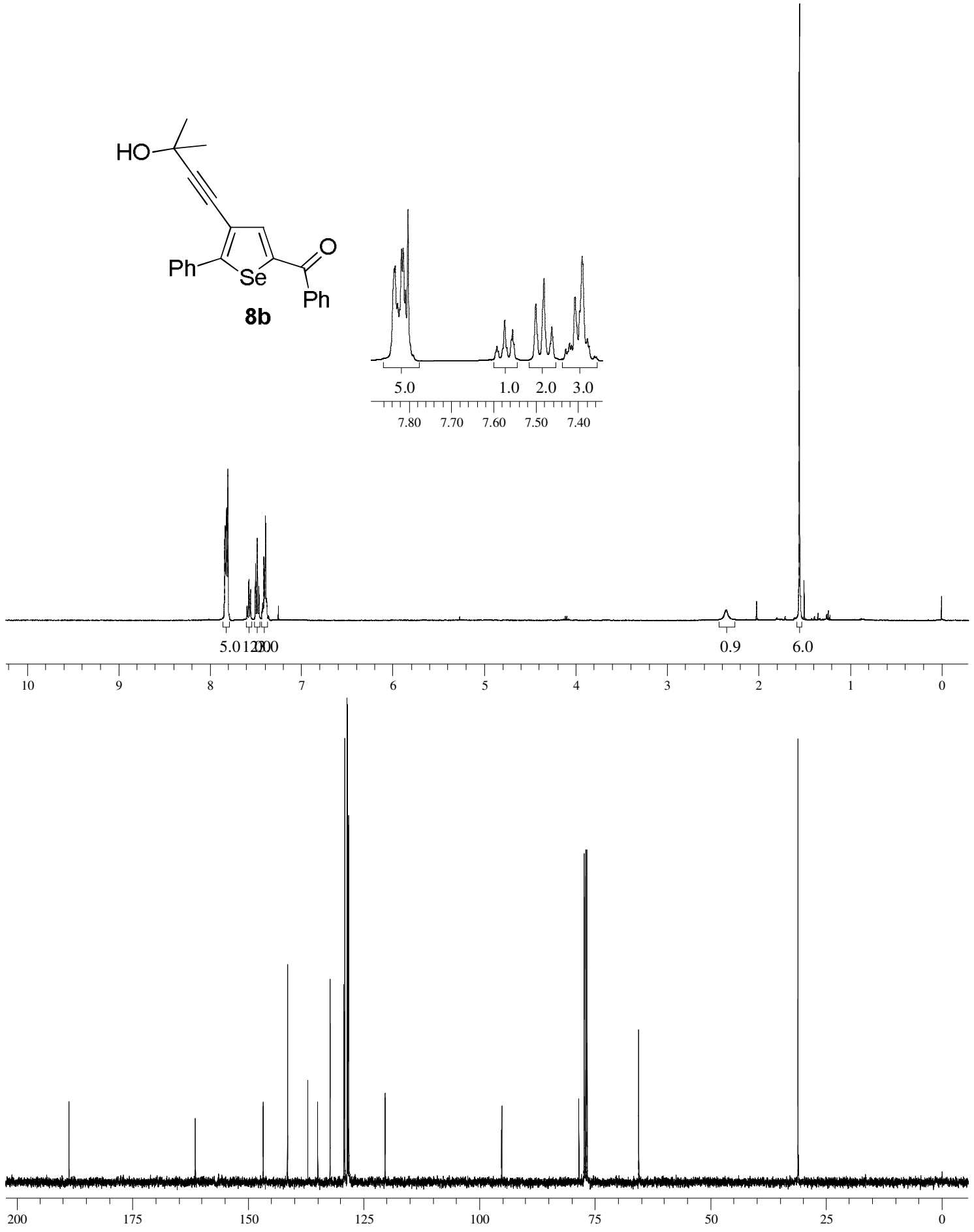

42 


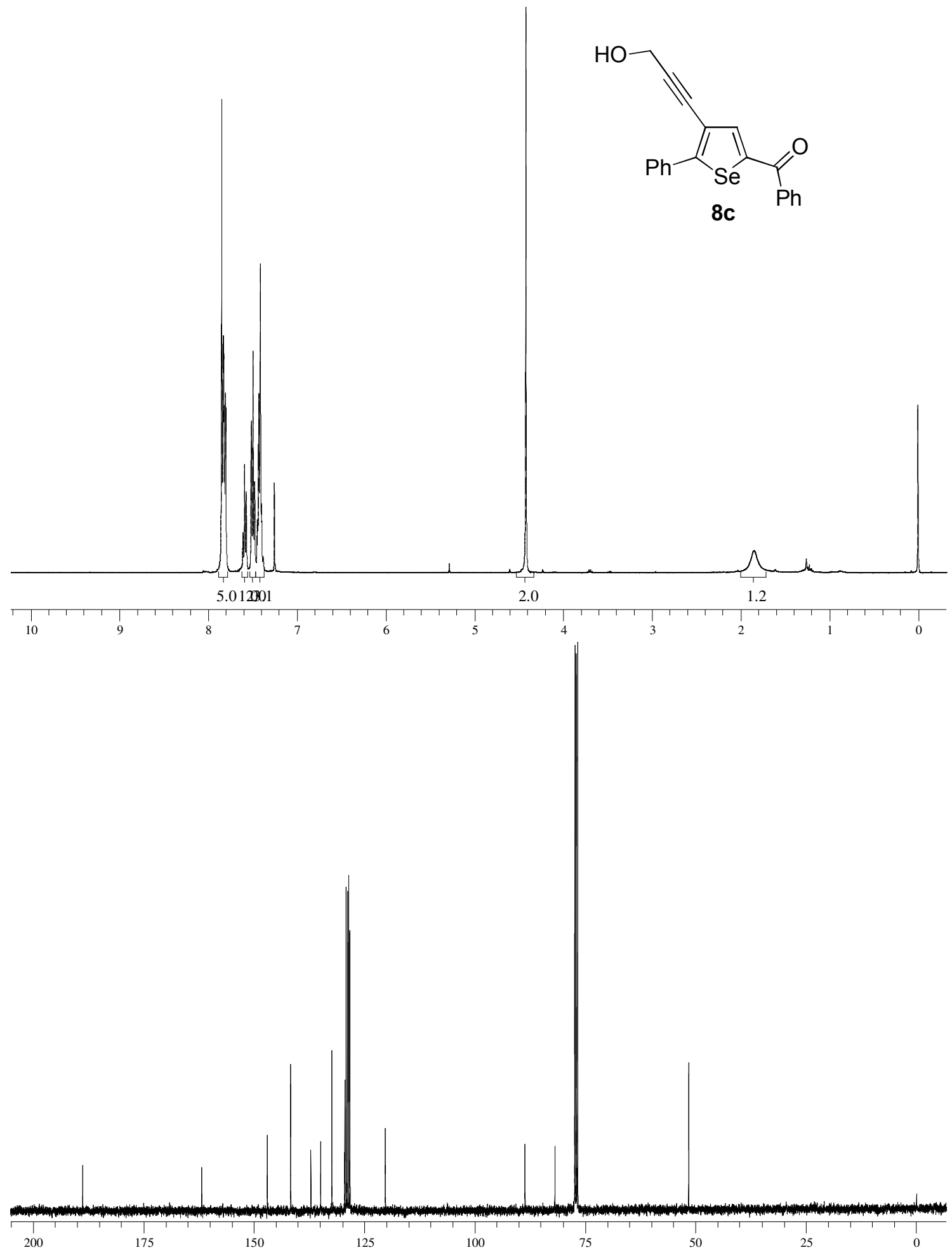

43 

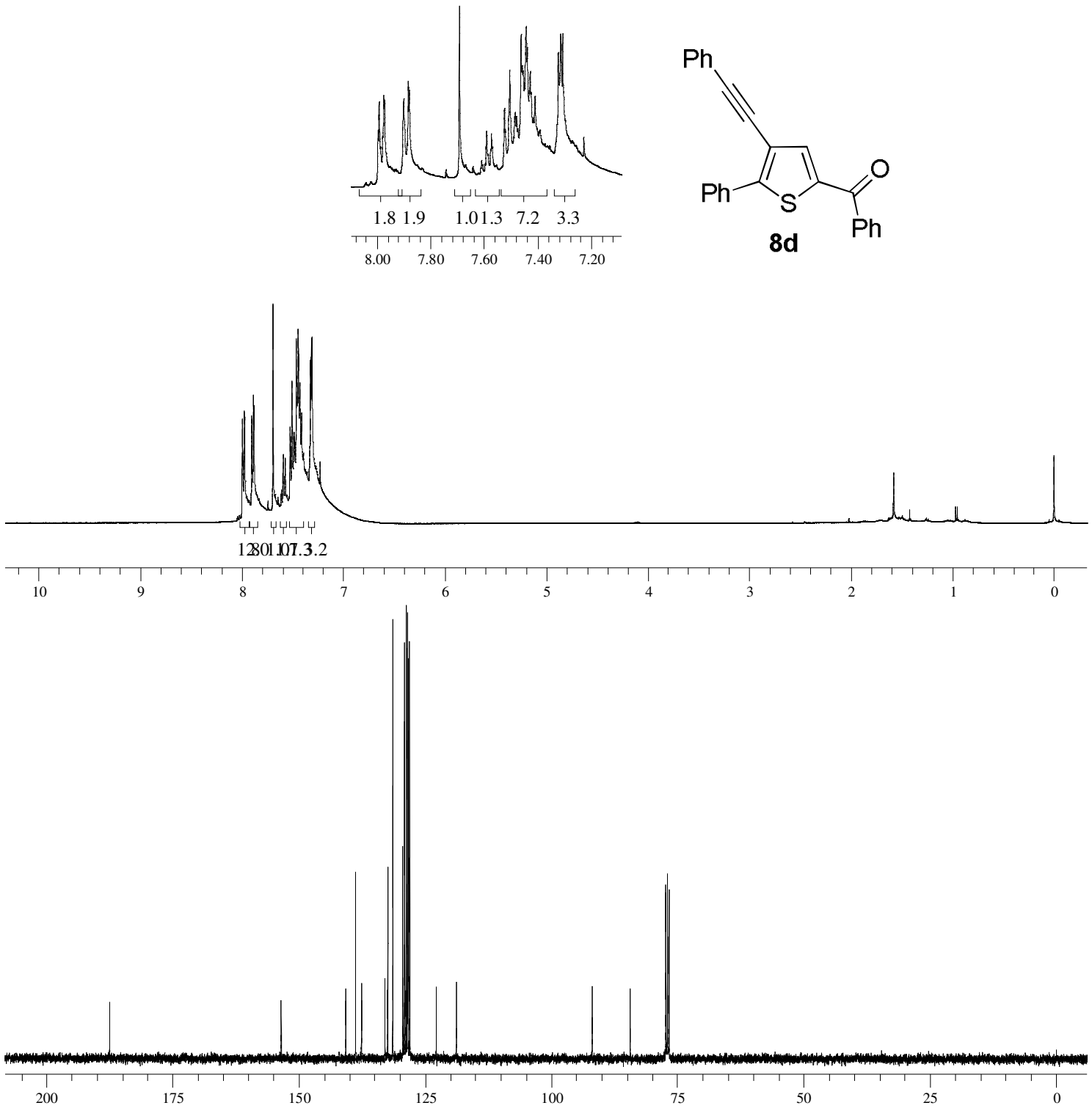

44 


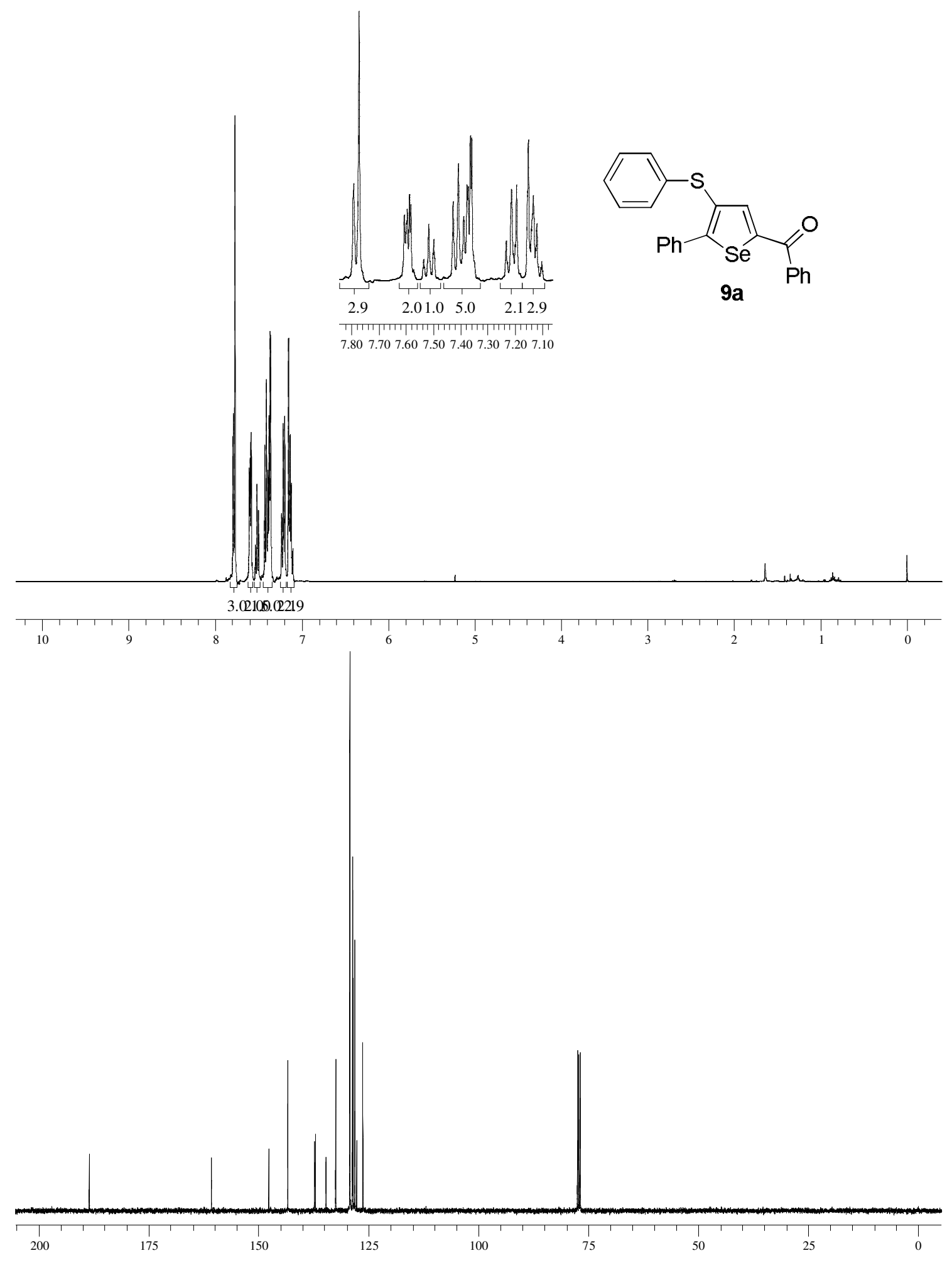




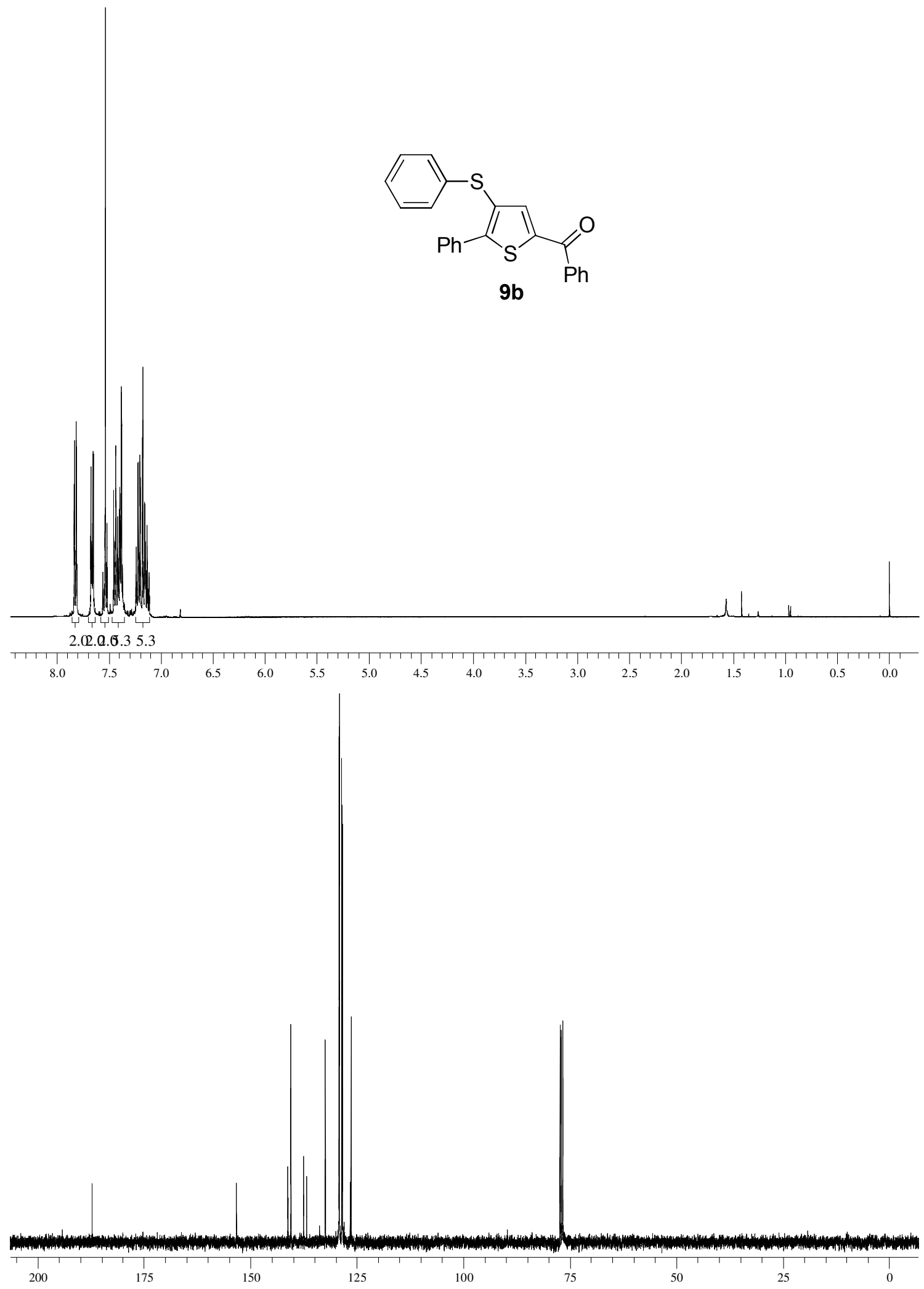

46 